$1-2016$

\title{
Robust Determinants of Intergenerational Mobility in the Land of Opportunity
}

Andros Kourtellos

Christa Marr

Chih Ming Tan

University of North Dakota, chihming.tan@UND.edu

How does access to this work benefit you? Let us know!

Follow this and additional works at: https://commons.und.edu/ef-fac

Part of the Economics Commons

\section{Recommended Citation}

Andros Kourtellos, Christa Marr, and Chih Ming Tan. "Robust Determinants of Intergenerational Mobility in the Land of Opportunity" (2016). Economics \& Finance Faculty Publications. 1.

https://commons.und.edu/ef-fac/1

This Article is brought to you for free and open access by the Department of Economics \& Finance at UND Scholarly Commons. It has been accepted for inclusion in Economics \& Finance Faculty Publications by an authorized administrator of UND Scholarly Commons. For more information, please contact und.commons@library.und.edu. 


\title{
Robust Determinants of Intergenerational Mobility in the Land of Opportunity
}

\author{
Andros Kourtellos* Christa Marr ${ }^{\dagger}$ Chih Ming Tan ${ }^{\ddagger}$
}

October 1, 2014

*Department of Economics, University of Cyprus, P.O. Box 537, CY 1678 Nicosia, Cyprus, e-mail: andros@ucy.ac.cy.

${ }^{\dagger}$ Christa Marr, Department of Economics, Rollins College, 1000 Holt Ave., Winter Park, FL 32789, USA, e-mail: christamarr@gmail.com.

${ }_{\ddagger}^{\ddagger}$ Department of Economics, University of North Dakota, 293 Centennial Drive Stop 8369, Grand Forks, North Dakota, USA, e-mail: chihming.tan@business.und.edu. 


\begin{abstract}
This paper revisits the influential work by Chetty, Hendren, Kline, and Saez (2014) who attempt to explain the variation in intergenerational mobility across commuter zones in the US (i.e., spatial mobility) using nine classes of variables. We employ Bayesian model averaging methods that allow for model uncertainty to identify robust predictors of spatial mobility. In doing so we pay special attention to the specification of model and parameter priors. We also investigate the heterogeneous effects of these predictors on spatial mobility across commuter zones in different average income quintiles. Our findings suggest a more nuance and complex characterization of the spatial mobility process than that proposed by Chetty, Hendren, Kline, and Saez.
\end{abstract}

Keywords: intergenerational mobility, income persistence, BMA, model uncertainty. JEL Classification Codes: C14, I14, I24. 


\section{Introduction}

There has been intense debate in the recent literature regarding intergenerational mobility how dependent an offspring's social and economic outcomes are on those of her parents - in the United States (and also other countries). The debate springs from two concerns. First, there has been substantial disagreement about the trend in intergenerational mobility across time. While some studies have shown that intergenerational mobility has declined over time, others have instead found that intergenerational mobility has always been consistently low; see, for example, Aaronson and Mazumder (2008), Lee and Solon (2009), Hauser (2010), the comprehensive survey by Corak (2013), and Clark (2014).

Getting an accurate picture about trends in intergenerational mobility is important not only because it informs the collective narrative about the nature of living in the United States - can the United States truly be characterized as the "land of opportunity" where inhabitants are able to overcome initial conditions through individual talent and hard work? - but also because it potentially informs policy makers about the nature of barriers to mobility.

The concern over the nature of intergenerational mobility is also important because of its relationship with income inequality. The recent literature has proposed a connection between income inequality and intergenerational income mobility popularized in the form of the Great Gatsby curve (see Krueger (2012) and Corak (2013)). The Great Gatsby curve describes the strong positive correlation between higher levels of inequality and lower degrees of mobility in the cross-section of high-income countries. In fact, the United States has one of the highest levels of inequality and lowest degrees of mobility among the high-income countries.

The question here is over the determinants of intergenerational mobility and whether factors that drive lower levels of intergenerational mobility may also account for the rise 
in higher degrees of income inequality. For example, Becker and Tomes (1979) refer to "endowments of capital that are determined by the reputation and 'connections' of their families, the contribution to the skills, race, and other characteristics of children from the genetic constitutions of their families, and the learning, skills, goals, and other 'family commodities' acquired through belonging to a particular family culture" that determine intergenerational mobility or lack thereof. Could these factors; perhaps in combination with others, also determine why some social groups are pulling away from others within the distribution of economic outcomes?

We focus in this paper on an influential recent paper by Chetty, Hendren, Kline, and Saez (2014) - henceforth, CHKS - who re-examine the trend in intergenerational mobility by focusing on children born in 1980-82 and their parents. CHKS address both concerns above in this paper. Their paper has quite a few novel features. First, they employ a comprehensive and reliable data set; i.e., federal income tax records. Second, instead of characterizing intergenerational mobility by estimating the intergenerational elasticity of earnings (IGE); i.e., by regressing the log income of children on the log income of parents, CHKS employ a rank-rank comparison instead. That is, they compare the rank of children to others in their birth cohorts with the rank of parents in relation to other parents with children in the aforementioned cohorts.

Using their rank-rank specification, CHKS were then able to estimate the degree of intergenerational mobility within each commuting zone (CZ) in the United States based on where children resided when they were 16 . They then attempted to explain the variation in intergenerational mobility across CZ's by considering 9 classes of covariates, or, as we will refer to them, "theories": (i) Segregation (e.g., Schelling (1971), Borjas (1995), Wilson (1996), Cutler and Glaeser (1997)), (ii) Income Distribution or Inequality (e.g., Corak (2013), (iii) Tax (e.g., Becker and Tomes (1979, 1986), Ichino, Karabarbounis, and Moretti (2011)), 
(iv) Quality of K-12 Education (e.g., Card and Krueger (1992)), (v) College Access, (vi) Local Labor Market (e.g., Autor, Dorn, and Hanson (2013)), (vii) Migration (e.g., Borjas and Katz (1997)), (viii) Social Capital (e.g., Coleman (1988)), and (ix) Family Structure (e.g., Becker (1991)). In total, CHKS consider over 30 variables associated with those 9 theories. Importantly, CHKS largely focus on simple univariate regressions from the large set of correlates on intergenerational mobility across CZ's. However, they also attempt to compare alternative hypotheses by running a horserace between a smaller set of selected variables meant to represent some of the most pertinent theories for explaining intergenerational mobility across CZ's. When they do so, they find that a set of five variables related to racial segregation, income inequality, the high school dropout rate, social capital, and the fraction of children with single parents exhibit the strongest and most robust correlations with spatial mobility. How persuaded should we be by their findings?

One implication of the above theories of social mobility is that they imply new channels of transmission beyond family income. The main problem in identifying the determinants of intergenerational mobility is that there do not exist good theoretical reasons to include a particular set of theories or proxies a priori. This is due to the fact that the theories of mobility are openended or mutually compatible. The validity of a theory of intergenerational mobility (e.g., Social Capital) does not logically exclude other theories from also being relevant (e.g., Segregation). The notion of openendedness was introduced by Brock and Durlauf (2001) in the context of economic growth who argued that this problem renders the coefficient estimates of interest to be 'fragile' in the sense of Leamer (1978). By fragility we mean that the estimated effect could change dramatically in magnitude, lose its statistical significance, or, even switch signs depending on which other (nuisance) variables are included or excluded in the regression equation. The potential fragility of coefficient estimates of mobility determinants under model uncertainty is important because it implies that findings 
on the intergenerational transmission process, which do not properly account for model uncertainty, may be non-robust.

To address the issue of model (and theory) uncertainty, we employ Bayesian model averaging (BMA) methods; see, e.g., Raftery, Madigan, and Hoeting (1997). These methods have seen wide application in other areas of economics; especially, in the area of empirical growth, but are novel to this literature. BMA moves the focus of analysis from estimates obtained from a given model to estimates that do not depend on a particular model specification but that are instead conditional on the model space. Since the model space is generated from the set of plausible explanatory variables for the dependent variable, a model is therefore simply a particular permutation of the set of explanatory variables. BMA accounts for model uncertainty by forming a weighted average of model-specific estimates where the weights are given by the posterior model probabilities.

In the implementation of BMA, care has to be taken in the specification of priors. In general, researchers are required to specify priors over model-specific parameters and also priors over models in the model space. In particular, we note the pioneering work of Eduardo Ley and coauthors; see, in particular, Fernandez, Ley, and Steel (2001a,b). As pointed out by Fernandez, Ley, and Steel (2001a), a key concern in the literature is that posterior model probabilities that is, the evidentiary weights that are used in BMA for averaging the estimates across models are sensitive to the specification of priors over model-specific parameters; see, also, Kass and Raftery (1995). In this paper we follow Fernandez, Ley, and Steel (2001a) and use their "Benchmark" priors in our baseline specifications. Additionally, we provide extensive robustness checks that investigate various other parameter and model prior structures; see for example Raftery (1995), George (1999), Eicher, Papageorgiou, and Raftery (2011), Ley and Steel (2012).

Our findings, once we have accounted for model uncertainty, suggest a more nuance and 
complex characterization of the spatial mobility process. We certainly do find that the five broad theories that CHKS have highlighted as being important for explaining spatial mobility are generally robust. However, the specific determinants within each of these theories that are important depend on the particular measure of spatial mobility employed in the analysis. We also found that other theories, above and beyond the five identified by CHKS, such as local labor market conditions and state fiscal policies also play potentially important roles in explaining the pattern of spatial mobility. Finally, we find substantial heterogeneity in the effect of mobility determinants on outcomes. The impact of particular determinants depends critically on whether the children grew up in urban areas and to which segment of the income distribution.

The rest of the paper is organized as follows. Section 2, which presents the standard regression framework of the analysis of the determinants of intergenerational mobility. Section 3 describes the data and replication results. Section 4 presents the BMA methodology. Section 5 describes our main empirical as well as robustness results. Section 6 concludes.

\section{Standard Regression Framework}

We revisit the analysis of CHKS on the determinants of intergenerational mobility using a more general framework that treats their specifications as particular examples of the linear regression model of intergenerational mobility. In particular, for each commuting zone $i$, we assume that the intergenerational mobility $\rho_{i}$ between parents and offspring is determined by the following linear regression model, denoted by $\mathcal{M}_{m}$,

$$
\rho_{i}=\alpha+x_{m i}^{\prime} \beta_{m}+e_{i}
$$


where $m=1, \ldots, M$ and $i=1, \ldots, n . x_{m i}$ is a set of $k_{m}$ regressors chosen from a larger set of $k$ regressors $x_{i}$ and $\beta_{m}$ is a vector of the corresponding regression coefficients. $\alpha$ is an intercept. We assume that $\operatorname{rank}\left(1_{n}, X\right)=k+1$, where $1_{n}$ is an $n$-dimensional vector of 1 's and $X$ is a stacked vector of $x_{i}$. Define $\beta$ as the $k$-dimensional vector of coefficients of the full regression of $\rho_{i}$ on $x_{i}$ and let $\beta$ be the object of interest. $e_{i}$ is assumed to be a Normal regression error, $e_{i} \mid x_{i} \sim N\left(0, \sigma^{2}\right)$, where $\sigma^{2}>0$. Finally, we assume that we observe a random sample $\mathcal{D}=\left\{\left(\rho_{i}, x_{i}\right)\right\}_{i=1}^{n}$. All the specifications considered in CHKS constitute particular choices of $x_{m i}$. Both their baseline investigations in Table VII, which are based on univariate models and their multivariate models in Table IX can be viewed as particular models.

\section{Data and Replication}

\subsection{Chetty-Hendren-Klein-Saez Data}

Following CHKS we use two measures of intergenerational mobility and 31 determinants across US commuting zones made available by the Equality of Opportunity Project ${ }^{1}$. Full descriptive statistics can be found in Table 1. More details can be found in the appendix of Chetty, Hendren, Kline, and Saez (2014).

Our sample differs in two dimensions. First, because the focus of our analysis is on multivariate analysis we balance our sample by eliminating missing observations. The balancing results in 509 commuting zones as opposed to the core sample of CHKS that includes 709 commuter zones. Second, due to multicollinearity issues we exclude from our analysis the following CHKS proxies: the segregation of poverty, the segregation of affluence,

\footnotetext{
${ }^{1} \mathrm{http}: / /$ www.equality-of-opportunity.org/
} 
the gini coefficient for parent income, and the fraction middle class. For robustness purposes, we also consider an extended sample that drops the college variables to increase the sample size to 633 commuting zones. $^{2}$

\subsubsection{Measures of Mobility}

Intergenerational mobility is a latent variable. The standard empirical approach in the literature estimates the intergenerational mobility using the intergenerational elasticity of income (IGE), which is the slope coefficient from a log-log linear regression model of children's permanent income on parents' permanent income controlling for some characteristics; see for example Blanden (2013) for an excellent recent survey. Instead, CHKS estimate the intergenerational mobility using a rank-rank LS regression between offspring's percentile rank based on their position in the distribution of Child Income within her birth cohorts and the percentile rank of the parents based on their position in the distribution of Parent Income. More precisely, for each $\mathrm{CZ} i$, CHKS estimate the following rank-rank regression

$$
r_{j i}^{o}=\delta_{0 i}+\delta_{1 i} r_{j i}^{p}+\varepsilon_{j i}
$$

where $r_{j i}^{o}$ denotes the national income rank of offspring $j$ among offsprings in her birth cohort who grew up in $\mathrm{CZ} i$ and $r_{j i}^{p}$ denotes the corresponding rank for her parent in the income distribution of parents in the core sample. Percentile ranks are measured on a 0-100 scale and slopes on a $0-1$ scale, so $\delta_{0 i}$ ranges from $0-100$ and $\delta_{1 i}$ ranges from 0 to 1 .

CHKS argue that rank-rank regressions avoid at least two problems of the standard log-log regression analysis. LS linear regression between the logarithm of Child Income and the logarithm of Parent Income is likely to yield biased mobility estimates because it

\footnotetext{
${ }^{2}$ The corresponding descriptive statistics can be found in Table A1.
} 
discards observations with zero income and omits nonlinearities. In contrast, a LS linear regression of a rank-rank model allows us to include zeros in Child Income and provides a good approximation of the conditional mean of a child's rank given her parents' rank, and hence, it does not suffer from bias due to omitted nonlinearities.

The data on Child and Parent Income are obtained from the IRS Databank and matching between parent and child is achieved using information from 1040 tax records. Children are assigned to the commuting zone reported in the 1040 record of their parents. CHKS's baseline analysis is based on a core sample of 1980-82 birth cohorts and measures Parent Income as the average parents' family income over the years 1996 to 2000 and Child Income as the mean family income in 2011-12, when children are approximately 30 years old.

Following CHKS, we consider two measures of intergenerational mobility: Relative Mobility and Absolute Upward Mobility. Relative Mobility, due to the linearity of the rankrank regression, measures the difference in income between the expected ranks of children born to parents at the top and bottom of the income distribution within a $\mathrm{CZ}$ and is given by the estimated slope in equation (3.2), i.e., $\widehat{\rho}_{i}=100 \widehat{\delta}_{1 c}$, of the rank-rank regression. Absolute mobility is defined as the expected child rank of children born to a parent whose national income rank is $p$ in a particular CZ. Absolute Upward Mobility measures the average absolute mobility for children from families with below median parent income. Given the linearity of the rank-rank relationship, the average rank of children with below-median parent income equals the average rank of children from families at the 25 th percentile of the national parent income distribution in equation (3.2), i.e., $\widehat{\rho}_{i}=\widehat{\delta}_{0 i}+25 \widehat{\delta}_{1 i}$. 


\subsubsection{Determinants}

The determinants of mobility are organized into nine different theories: Segregation, Income Distribution, Tax, K-12 Education, College, Local Labor Market, Migration, Social Capital, and Family Structure.

Following CHKS we investigate the effects of Segregation on intergenerational mobility by focusing on three alternative aspects of segregation - racial, income, and geographical using data from the 2000 Census. For racial segregation, we include a Theil Index and the Fraction of Black Residents in each commuting zone. For income segregation we use a Theil Index, which is based on a weighted average of two groups. For geographical segregation we include the Share with Commute $<15$ Mins, which is the number of commuters who commute less than 15 minutes over the total number of commuters in each zone.

Income Distribution is measured using the mean level of Household Income per Capita for Working-Age Adults in a CZ, the Gini Bottom 99\%, and the Top 1\% Income Share for Parents within each CZ. It is worth mentioning that CHKS were very careful to use the same income information as the one used for the estimation of mobility.

Tax is measured using four variables. The Local Tax Rate and the Local Government Expenditures per capita are based on data from the U.S. Census Bureau's 1992 Census of Government county-level summaries. State Income Tax Progressivity uses data from the Tax Foundation to measure the difference between 2008 state income tax rates for incomes in the top bracket (above $\$ 100,000$ ) and incomes in the bottom tax bracket. The State Earned Income Tax Credit (EITC) Exposure is obtained from Hotz and Scholz (2003) using yearly rates over the 1980-2001 period.

K-12 Education is measured using four variables: the Teacher-Student Ratio, which is based on 1996-97 school-level data, the School Expenditures, which are measured using 
1996-97 school district data, the High School Dropout Rates, which are measured using 2000-01 school district data, and the Test Score Percentile controlling for Parent Income. The first three variables are based on data from the National Center for Education Statistics' Common Core of Data for public schools while the test scores are constructed using a weighted mean from the 2004, 2005, 2007 from Global Report Card (National Math and Reading Percentiles).

College is measured using three variables constructed from the Integrated Postsecondary Education Data System (IPEDS). The Number of Colleges per Capita is measured from the 2000 data while the College Graduation Rate (controlling for Parent Income) for each CZ is based on the 2009 data. The Mean College Tuition is the mean in-state tuition (and fees) for full-time, first-time undergraduates.

Local Labor Market is measured using four variables. The Labor Force Participation Rate is based on the 2000 US Census. The Teenage (14-16) Labor Force Participation is constructed as the number of children born from 1985-1987 who receive a W2 out of the total number of children in each zone. The Fraction Working in Manufacturing is computed from 2000 Census by dividing the number of people working in manufacturing by the total number of workers. And the Growth in Chinese Imports is based on Autor, Dorn, and Hanson (2013) and measures the per-worker change in imports from China between 1990 and 2000. At the commuting zone level, it is calculated as the growth in imports allocated to a zone, divided by the 1990 zone work force.

Migration is measured by the Migration Inflow Rate, the Migration Outflow Rate using county-to-county migration statistics from the Internal Revenue Service's Statistics of Income for 2004 to 2005, and the Share of Foreign Born Residents in each CZ based on the 2000 US Census. 
Social Capital is measured by three variables. The Social Capital Index is taken from Rupasingha and Goetz (2008) who construct a 1990 county-level social capital index. The Fraction of Religious residents is based on the self-reported number of religious adherents from the Association of Religion Data Archives at Pennsylvania State University. The Violent Crime Rate in each zone is measured using the FBI's Uniform Crime Reporting program obtained from county-level ICPSR data. More precisely, it is computed as the ratio of the total number of arrests for serious violent crimes to the total covered population.

Family Structure is measured using three variables from 2000 US Census: the Fraction of Adults Divorced, the Fraction of Adults Married, and the Fraction of Children with Single Mothers. The fraction of children with single mothers is constructed as the number of households with female heads with own children present (and no husband present) divided by the total number of households with own children present in each CZ.

\subsection{Replication Results: Univariate and Short Regressions}

A key focus of CHKS is the univariate regression analysis reported in Table VII of their paper. In particular, CHKS consider univariate regressions of absolute and Relative Mobility on 35 variables from the nine theories listed above. We begin by replicating this key table. We present our replication results in Table 2. Despite the fact that our sample is essentially a subsample of CHKS and we only use 31 variables, we closely replicate their regression results. Like CHKS we find that there is strong evidence that all of the 9 theories potentially predict

spatial mobility (however measured) with some predictors within each theory being stronger than others. In unreported exercises we investigated the effect of switching some of the included variables with the ones that we excluded but our results remained unaffected.

We also replicate their preferred multivariate regressions in Table IX using our sample. 
CHKS argue that five theories exhibit the strongest and most robust correlations with intergenerational mobility: Segregation, Income Inequality, School Quality, Social Capital, and Family Structure. They then run regressions of the spatial mobility measures on the following 5 proxy variables: Racial Segregation Theil Index, Gini Bottom 99\%, High School Dropout Rate, Social Capital Index, Fraction Single Mothers, and Fraction Black. They conclude that the variation in spatial mobility is explained by a combination of the above 5 theories and their proxies rather than any single theory. We refer to this kind of analysis as "short regressions" to emphasize the fact that CHKS only include a particular subset of the 35 regressors. Our replication results in Table 3 are substantively similar to their findings in Table IX, albeit with small differences in the magnitude of the coefficients due to the differences in the two samples. ${ }^{3}$

\section{BMA Methodology}

A direct implication of theory uncertainty is that no individual model in equation (2.1) can be viewed a priori as the true one. This includes the case when equation (2.1) is the full model. Ignoring issues of multicollinearity and the fact that the sample size $n$ can be smaller than $k$, the full model is just a single model in the set of all $2^{k}$ possible combinations of regressors from the vector $x_{i}$, and may potentially have weak evidentiary support. This set defines the model space and is denoted by $\mathcal{M}=\left\{\mathcal{M}_{1}, . ., \mathcal{M}_{M}\right\}$. So how can one obtain robust statistical inference for statistics of interest that does not depend on a specific choice of determinants but rather depends on a model space whose elements span an appropriate range of determinants suggested by a large body of work? To deal with this problem we employ a Bayesian Model Averaging (BMA) approach to identify robust determinants of

\footnotetext{
${ }^{3}$ In the Appendix we also provide the replication of Table IX using our extended sample with similar results; see Table A2.
} 
intergenerational income mobility. BMA dates back to Leamer (1978), and was further studied by Draper (1995), Kass and Raftery (1995), and Raftery, Madigan, and Hoeting $(1997){ }^{4}$

BMA integrates out the uncertainty over models by computing the posterior distribution of $\beta, \widehat{\mu}(\beta \mid \mathcal{D})$, as a weighted average of model-specific posterior distributions of $\beta$, $\widehat{\mu}\left(\beta \mid \mathcal{M}_{m}, \mathcal{D}\right)$,

$$
\widehat{\mu}(\beta \mid \mathcal{D})=\sum_{m=1}^{M} \widehat{w}_{m} \widehat{\mu}\left(\beta \mid \mathcal{M}_{m}, \mathcal{D}\right),
$$

with weights $\widehat{w}_{m}$ given by the posterior model probabilities of model $\mathcal{M}_{m}$, which are computed via Bayes' rule

$$
\widehat{w}_{m} \equiv \widehat{\mu}\left(\mathcal{M}_{m} \mid \mathcal{D}\right)=\frac{\widehat{\mu}\left(\mathcal{D} \mid \mathcal{M}_{m}\right) \mu\left(\mathcal{M}_{m}\right)}{\sum_{m=1}^{M} \widehat{\mu}\left(\mathcal{D} \mid \mathcal{M}_{m}\right) \mu\left(\mathcal{M}_{m}\right)}
$$

where $\widehat{\mu}\left(\mathcal{D} \mid \mathcal{M}_{m}\right)$ is the integrated likelihood (also known as the marginal likelihood) of the data given a model and $\mu\left(\mathcal{M}_{m}\right)$ is the prior probability for a model. The denominator is the total posterior mass, which is constant over all models.

Deferring the discussion on the parameter and model priors for the subsections below, the BMA estimator of $\beta$ takes the form of a weighted average of model-specific coefficient estimates

$$
\widehat{\beta}_{B M A}^{\mathcal{M}}=\sum_{m=1}^{M} \widehat{w}_{m} \widehat{\beta}_{m}
$$

where $\widehat{\beta}_{m}$ is the LS estimator of $\beta_{m}$ in model $\mathcal{M}_{m}$ and with standard errors based on the

\footnotetext{
${ }^{4}$ BMA has proven to be particularly useful in identifying robust growth determinants; see for example, Brock and Durlauf (2001), Fernandez, Ley, and Steel (2001b), Sala-i Martin, Doppelhofer, and Miller (2004), Durlauf, Kourtellos, and Tan (2008), and Masanjala and Papageorgiou (2008).
} 
corresponding model averaging variance estimator

$$
\widehat{V}_{B M A}^{\mathcal{M}}=\sum_{m=1}^{M} \widehat{w}_{m} \widehat{V}_{m}^{\beta}+\sum_{m=1}^{M} \widehat{w}_{m}\left(\widehat{\beta}_{m}-\widehat{\beta}_{B M A}^{\mathcal{M}}\right)^{2}
$$

where $\widehat{V}_{m}^{\beta}$ is the model specific variance matrix of $\widehat{\beta}_{m}$. The first term captures the variance of the within model estimates and the second term captures the variance of model-specific estimates across models. The latter is an additional source of variance, which does not arise when computing variances in the absence of model uncertainty. The notation $\widehat{\beta}_{B M A}^{\mathcal{M}}$ and $\widehat{V}_{B M A}^{\mathcal{M}}$ emphasizes the dependence of the estimator on the model space $\mathcal{M}$ instead of an individual model $\mathcal{M}_{m}$.

The standard way to conduct inference in the context of BMA is to reference the posterior probability of inclusion (PIP) for each regressor. The PIP is computed as the sum of the posterior probabilities of all the models that contain that variable. Following Sala-i Martin, Doppelhofer, and Miller (2004) and Durlauf, Kourtellos, and Tan (2008) we also report BMA posterior t-statistics for coefficient estimates and interpret them in the classical sense. Our approach can be viewed as a "hybrid" approach to BMA, which mixes frequentist probability statements about observables given unobservables with Bayesian probability statement about unobservables given observables. So while $\widehat{\beta}_{B M A}^{\mathcal{M}}$ and $\widehat{V}_{B M A}^{\mathcal{M}}$ are Bayesian objects, namely, the posterior mean and variance of $\beta$ given data, we report BMA posterior t-statistics for coefficient estimates and interpret them in the classical sense. ${ }^{5}$

Equations (4.3) and (4.4) imply that to operationalize BMA, we need make decisions regarding the prior model probabilities, prior parameter probabilities, and model space. ${ }^{6}$

\footnotetext{
${ }^{5}$ One problem with this kind of inference is that the asymptotic distribution of the t-statistic is a mixture of Normal distributions and hence, standard asymptotical Normal inference can be misleading.

${ }^{6}$ Our model space is constructed using the birth-death MCMC sampler based on $10^{6}$ burn-ins and $210^{6}$ draws. Our BMA results are also based on aggregate information from the sampling chain with posterior model distributions based on MCMC frequencies. However, as is evident from the bottom figure in Figure 1 the differences from an exact likelihood approach are practically indiscernible.
} 
The assumption about the prior distribution of parameters is required in order to obtain the model-specific posterior probability and the marginal likelihood. A simpler alternative to specifying explicit priors is to approximate the posterior model probability by the exponential of the Bayesian information criterion (BIC). This approximation is justified when a unit information prior for parameters and a uniform model prior are assumed; see Raftery (1995) and Kass and Wasserman (1995).

\subsection{Parameter Priors}

The standard BMA approach assumes that $\alpha$ is independent of $\beta$ and $\sigma^{2}$ so that $\mu(a, \beta, \sigma)=$ $\mu(a) \mu\left(\beta \mid \sigma^{2}\right) \mu\left(\sigma^{2}\right)$. Following Fernandez, Ley, and Steel (2001a) it is also typical to assume improper uninformative priors $\mu(\alpha) \propto 1$ and $\mu(\sigma) \propto \sigma^{-1}$ for $\alpha$ and $\sigma$, respectively. However, given that the number of regressors $k$ is typically large and in many cases $k \approx n$ or even $k>n$, there is a need for an informative prior for $\beta$. Fernandez, Ley, and Steel proposed the following prior distribution

$$
\mu\left(\beta_{m} \mid \sigma^{2}\right)=N\left(0, \sigma^{2}\left(g X_{m}^{\prime} X_{m}\right)^{-1}\right)
$$

where the variance of the prior distribution includes a shrinkage factor (or hyperparameter) $g$ known as the "Zellner's g prior". 7 The hyperparameter $g$ captures the prior belief of the econometrician on the parsimony of the model. A large $g$ corresponds to the belief that the size of the true model is small, that is, many coefficients are indeed zero while a small $g$ means that a larger model is more likely to be the true model. When $g \rightarrow 0$ we obtain the LS estimator of the full model.

The above g-prior framework yields a simple closed form solution for the marginal

\footnotetext{
${ }^{7} X_{m}$ is defined by stacking the vector $x_{m i}$.
} 
likelihood $\widehat{\mu}\left(\mathcal{D} \mid M_{m}\right)$ that is invariant under scale transformations. This marginal likelihood is a function of the $R^{2}$ and a model size penalty factor $k$. This simplicity and the invariance property are considered important advantages over more traditional Bayesian priors such as the Gamma priors.

Effectively, the choice of the prior distribution of $\beta$ has been transformed into the simple choice of a single parameter. Different choices of $g$ correspond to different prior structures. Several studies have investigated the performance of different priors; see for example, Fernandez, Ley, and Steel (2001a), Liang, Paulo, Molina, Clyde, and Berger (2008), Eicher, Papageorgiou, and Raftery (2011), and Ley and Steel (2012). Following Fernandez, Ley, and Steel our baseline prior is based on their benchmark priors (g-BRIC), which correspond to $g=\max \left(n, k^{2}\right)$. For robustness purposes we also report full results in Appendix using the Unit Information Prior (g-UIP), which corresponds to $g=n$.

Following Liang, Paulo, Molina, Clyde, and Berger (2008) we also investigate the robustness of our main findings using a more flexible prior structure that assumes a hyperprior on $g$,

$$
\frac{g}{1+g} \sim \operatorname{Beta}(1,(a-1) / 2)
$$

We consider two choices for $a$ : "hg-UIP" that corresponds to $a=2+2 / n$ and "hg-BRIC" that corresponds to $a=2+2 / \max \left(n, k^{2}\right){ }^{8}$

\footnotetext{
${ }^{8}$ In an unreported exercises we also considered the "Empirical Bayes - Local" (EBL), which is another flexible prior that correspond to $g_{m}=\max \left(0, F_{m}-1\right)$, where $F_{m}$ is the F-statistic; see Liang, Paulo, Molina, Clyde, and Berger (2008).
} 


\subsection{Model Priors}

The most popular structure for model prior probabilities is based on Mitchell and Beauchamp (1988)

$$
\mu\left(M_{m}\right)=\Pi_{l=1}^{k} \pi^{d_{l}}(1-\pi)^{1-d_{l}},
$$

where $d_{l}$ is an indicator function that takes value 1 or 0 when variable $l$ is included or excluded in model $M_{m}$, respectively. As our baseline model prior we use the Uniform Model Prior, which implies that the prior probability that any variable is included in the true model is $\pi=0.5$. This prior is not only simple but it also exhibits superior performance. For example, in an important recent paper, Eicher, Papageorgiou, and Raftery (2011) compare the cross-validated predictive performance of various parameter prior specifications including both the UIP and the g-prior. They also considered two specifications for model priors; i.e., the uniform prior and a prior that pre-specifies the expected model size. They find that the UIP with the uniform model prior generally outperformed the other model specifications.

However, there are good reasons as to why a uniform model prior may not be appropriate in every setting. As argued by Brock and Durlauf (2001) the uniform prior creates a problem that is analogous to the irrelevance of independent alternatives (IIA) in the discrete-choice literature by ignoring interrelations between different variables. ${ }^{9}$ In our context this implies that the probability that one variable affects spatial mobility may be logically dependent on whether others do as well. Since one goal of our study is to evaluate the relative importance of various theories of spatial mobility (as opposed to individual proxy variables), we require that our model priors capture non-informativeness (i.e., agnosticism) across theories. The problem with the uniform prior is that a researcher can increase or reduce the prior weights

\footnotetext{
${ }^{9}$ The IIA problem is also known as the red bus/blue bus problem. In the logit model, the presence of the blue bus does not affect the ratio of the choice probabilities between a red bus and a taxi. This poses a problem, however, since the blue bus is identical in all but color to the red bus, that is a close substitute, while the taxi is not.
} 
across theories simply by intelligently choosing "redundant" proxy variables for each theory. To deal with this problem we consider two sets of robustness exercises that use hierarchical priors and dilution priors. Brock and Durlauf (2001) proposed a tree structure to construct prior probabilities. In particular, the set of variables in $M_{j}$ are classified into $T$ theories. Priors are defined across theories and over variables within theories. The prior probability that a particular theory is included in the "true" model is assumed to be 0.5 to reflect a flat non-informative prior across theories. This prior specification also assumes that theories are independent in the sense that the inclusion of one theory in a model does not affect the probability that some other theory is also included.

Following George $(1999,2010)$ we employ a tessellation defined dilution prior in order to dilute the prior model probabilities of clusters of similar models by assigning uniform probabilities to neighborhoods of models rather than to individual models. The neighborhoods are defined by appropriate regions of the surface of a high dimensional sphere, which form Voronoi tessellations; see Moser and Hofmarcher (2014) for details on the implementation of this idea. ${ }^{10}$

\section{BMA Results}

\subsection{Baseline Exercises}

We now report results from our BMA regressions that consider the entire model space based on all 31 variables, and not just a selected subset of models. How credible were the models proposed by CHKS? The top panel of Figure 1 shows the distribution of model sizes for our

\footnotetext{
${ }^{10}$ Our choice of informative priors does not imply that other alternatives may not be appropriate; see for example the BACE approach of Sala-i Martin, Doppelhofer, and Miller (2004), the hierarchical priors with dilution proposed by Durlauf, Kourtellos, and Tan (2008) and Magnus and Wang (2014).
} 
baseline exercise. What appears to be clear is that neither the univariate models considered in Table VII nor the 5-variable regression model in Table IX of CHKS enjoy particularly strong support by the data. The posterior probability for models of those sizes is effectively negligible. This is true not just for our baseline specification, but also for any of the prior specifications we discussed in Section 4 above. In fact, the posterior mean for model size using our benchmark specification is 14 suggesting that the process governing spatial mobility is relatively complex. What about the 5 variable/hypotheses highlighted by CHKS as the strongest and most robust correlates with spatial mobility? We now ask whether the 5 determinants favored by CHKS show at least strong evidence for an effect (i.e., have a PIP greater than $95 \%){ }^{11}$

Table 4 shows the PIP for each of the variables in the model space while Table 5 shows the corresponding posterior means and standard errors. We focus first on Absolute Upward Mobility. Figure 2 provides a graphical representation of the PIP of variables for the Baseline exercise for Absolute Upward Mobility focusing on the top 100 models with the strongest posterior support (i.e., highest posterior model probabilities). What is clear from Tables 4 and 5 , and Figure 2 is that (i) not all the 5 CHKS variables are important determinants of spatial mobility, and (ii) there are other variables outside of these 5 that nevertheless are also important determinants and their existence changes the nature of the narrative around what explains the variation in mobility across CZ's in the US.

There is certainly prima facie evidence that there is a racial component to spatial mobility. Our BMA results agree with CHKS that the Theil index of racial segregation is an (perhaps the most) important in explaining the variation of mobility across CZ's. However, our BMA results do not find that the fraction of black residents has a negative impact on

\footnotetext{
${ }^{11}$ We follow the interpretation of PIP proposed by Eicher, Henn, and Papageorgiou (2012) and Kass and Raftery (1995): PIP $<50 \%$ indicates lack of evidence for an effect, $50 \%<\mathrm{PIP}<75 \%$ indicates weak evidence for an effect, $75 \%<\mathrm{PIP}<95 \%$ indicates positive evidence for an effect, $95 \%<\mathrm{PIP}<99 \%$ indicates strong evidence for an effect, and $99 \%<\mathrm{PIP}<100 \%$ indicates decisive evidence for an effect.
} 
Absolute Upward Mobility (as was the case in CHKS' univariate results), even though this variable is shown to be highly important in terms of PIP. In fact, our BMA findings suggest that CZ's with higher fractions of black residents enjoy higher levels of Absolute Upward Mobility when other determinants have been controlled for. The story here therefore appears to be about segregation and not race itself. This narrative is further strengthened by the fact that the share of commuters with a commute of under 15 minutes; another measure of segregation, also turns out to be a highly important and positively significant predictor of spatial mobility.

It is also true that variables associated with K-12 Education (the high school dropout rate), Social Capital (the social capital index), and Family Structure (the fraction of children with single mothers) all enjoy strong posterior support for being important explanations for spatial mobility (at least for some of the regression specifications) and with the direction of effect predicted by CHKS. However, a lot is left out of the narrative if we only focus on these three particular variables. For instance, for the case of Social Capital, the BMA evidence suggests that it is not only the social capital index that is associated with higher Absolute Upward Mobility. The same also holds for the fraction of the population that self-report to be religious adherents. While it certainly appears to be true that secondary schooling systems and family structures that are placed under stress are associated with worse mobility outcomes, it is also true that the changing nature of the local labor market (the fraction of the workforce in manufacturing) and state fiscal policies (state income tax progressivity) contribute importantly to Absolute Upward Mobility as well. And, for income inequality, our BMA results suggest that it is not what is happening with the bottom $99 \%$ of the income distribution that is important, but rather the income share of the top 1\% (although the negative effect is only significant for the specification where state fixed effects are included in the regression). The bottom $99 \%$ Gini coefficient is not an important explanation for 
Absolute Upward Mobility at all.

Our BMA results also suggest that the determinants that are important for Absolute Upward Mobility are not necessarily similar to the ones that are important for explaining Relative Mobility or even Absolute Upward Mobility in urban areas. For instance, while racial segregation and social capital are important determinants in explaining Relative Mobility, when it comes to theories like Income Distribution, K-12 Education, the Local Labor Market, and Family Structure, the determinants that are relevant for explaining Relative Mobility differ considerably from those that explain Absolute Upward Mobility. For Relative Mobility, it is the level of household income per capita for working-age adults rather than the distribution of income that appears to be important, it is the performance of students in terms of test scores rather than their drop out rate that matters, the children of divorced parents are able to overcome their initial disadvantages and close the gap relative to their peers, the availability of cheap imports improves Relative Mobility while the importance of manufacturing is of no consequence, while the rate of migration inflows puts pressure on Relative Mobility. Similarly, for residents in urban areas, it is variables like the level of household income, the accessibility of higher education (mean college tuition), the impact of foreign import competition, violent crime, and the fraction of adult divorces that affect Absolute Upward Mobility.

Overall, our BMA results paint a picture of nuance and complexity when explaining spatial mobility. The determinants that are important depend on whether we are concerned with the relative within-cohort rankings of children relative to those of their parents (Relative Mobility), or, if we are interested only in the relative within-cohort rankings of children born to parents from the lower half of the income distribution (Absolute Upward Mobility). These determinants also depend on whether these children grew up in urban areas. 


\subsection{Robustness}

In terms of robustness checks, we consider four different sets of exercises. First, we consider two individual models of our model averaging model space: the posterior mode model in Table 6 and the full (largest) long regression model in Table 7. From the Bayesian perspective, if a researcher prefers to select a model from the model space rather than engage in model averaging, the posterior mode model would be the one that is best supported by the data. However, as the 2 nd panel in Figure 1 shows, even the posterior mode model is not a model that enjoys overwhelming support; it has a posterior model probability of only just slightly more than $8 \%$. Nevertheless, we find that the conclusions we made from the BMA exercises reported in the above section are borne out in the findings for the posterior mode model. Hence, even if the researcher insists on selecting a model from the model space, the main findings would not vary.

The full model includes all the available determinants of mobility and it is typically reported in standard regression analysis. It is a low-bias model (at the cost of reduced efficiency) with potentially many irrelevant covariates, which nests all models that belong in $\mathcal{M}$. This model, however, has a negligible posterior model probability suggesting that it is a rather poor model. In general, the number of significant variables implied by the classical analysis based on the BMA regression model in Table 5 is much smaller than the one in the full regression model. While in some cases the set of significant variables in the BMA analysis is a subset of the one in the full regression analysis (e.g., the baseline specification) there are also several cases where the BMA analysis identifies significant variables that the full model does not. For example, in the case of Relative Mobility the BMA analysis shows that Household Income per capita is a decisively important as well as a strongly significant variable. In contrast, using the long full regression analysis we find that Household Income per capita is not a significant determinant of Relative Mobility. 
Second, we report BMA results in Tables 8 and 9 using our extended sample that excludes the College variables. In general, we find that the analysis in the above section is robust to the exclusion of the College variables (and the increase in sample size). We find that College variables did not play a major role in CHKS' analysis, and did not show strong evidence for a significant effect on either of the mobility measures in our BMA exercises in Tables 4 and 5. By dropping these variables, we were able to increase the sample size (while still keeping the sample balanced) to be closer to that of CHKS' univariate analysis.

Third, following our discussion in Sections 4.1 and 4.2 we we investigate the robustness of our choice of baseline priors: uniform model priors and g-BRIC. In Tables 10 and 11, we report the PIP and coefficient estimates and standard errors results for BMA exercises for the Baseline regression model for Absolute Upward Mobility for combinations of 3 alternative model priors (uniform, hierarchical, and tesselation defined dilution) with 4 alternative parameter priors; 2 fixed parameter priors (g-BRIC, g-UIP) and 2 flexible parameter priors (hg-BRIC, hg-BRIC). Employing tesselation model priors instead of the baseline uniform model priors leads to no qualitative changes. However, moving from uniform model priors to a hierarchical model prior structure does lead to one major change. While in the benchmark case, both the racial segregation Thiel index and the fraction of black residents are important predictors of Absolute Upward Mobility, only the fraction of black residents remains important under hierarchical model priors. In Tables A3 and A4 of the Appendix we also report full results that correspond to Tables 4 and 5 using uniform model prior and g-UIP. Compared to our benchmark exercises, it appears that variations in parameter priors specifications do not change the results. Overall, our findings appear to be very robust to changes in prior structures.

Finally, we examine in Table 12 the question of whether the effects of the various predictors of Absolute Upward Mobility exhibit heterogeneity across the distribution of CZ's 
organized according to the average income of parents within the CZ. We report the PIP, posterior mean, and posterior standard error for the Baseline model in Tables 4 and 5 for each quintile of CZ's according to income. We do find strong evidence of heterogeneity in terms of the determinants that explain spatial mobility across socioeconomically dissimilar neighborhoods. We do also find that some previously identified determinants are consistently important across these neighborhoods.

For example, in terms of the effects of segregation on mobility, the share of commuters with commutes below 15 mins was found to be important and to have a positive impact on Absolute Upward Mobility across CZ's for all income quintiles with a relatively stable coefficient estimate. Similarly, the share of manufacturing in the local labor market as well as the fraction of children with single mothers both exhibit important and negative effects on Absolute Upward Mobility across all income quintiles. In contrast, income distribution variables such as household income per capita or the top $1 \%$ income share for parents only affect residents in CZ's in the lowest or highest incomes, respectively. Children of higher income households living in the poorest 5th of CZ's enjoy higher rates of Absolute Upward Mobility, while children of households residing in the richest 5th of CZ's with higher income shares for the top $1 \%$ tend to face lower prospects of upward mobility (presumably because they are already from exceptionally rich backgrounds and therefore experience mean reversion). Finally, it is interesting to point out that different proxies for social capital appear to influence the mobility prospects of residents in different quintiles of the income distribution. While both the social capital index and the fraction of self-reported religious residents both exert important and significant positive effects on Absolute Upward Mobility, the former (emphasized by CHKS) appears to only impact residents in the 1st quintile of the income distribution. In contrast, the fraction of self-reported religious residents affects the mobility prospects of the top 3 quintiles of the income distribution. 
Overall, our results suggest that much more attention needs to be paid to the question of how determinants that affect intergenerational mobility exhibit potentially very heterogeneous effects across neighborhoods with different social characteristics. The story of what drives upward mobility for one social group may vary considerably from the narrative for another.

\section{Conclusion}

In this paper we assess the evidentiary support for various determinants of intergenerational mobility across commuter zones in the US. In particular, we revisit the influential work by Chetty, Hendren, Kline, and Saez (2014) who considered over 30 determinants of spatial mobility from nine different classes (theories): Segregation, Income Distribution, Tax, Quality of K-12 Education, College Access, Local Labor Market, Migration, Social Capital, and Family Structure. They found that a set of five variables related to racial segregation, income inequality, the high school dropout rate, social capital, and the fraction of children with single parents exhibit the strongest and most robust correlations with two measures of mobility: Absolute Upward Mobility and Relative Mobility. Our goal in this paper is to evaluate the strength of their claims using BMA methods in order to account for model uncertainty. In the implementation of BMA, we pay particular attention to the specification of model and parameter priors.

Once we account for model uncertainty we find a more nuance and complex picture of the spatial mobility process suggesting that their claims may be incomplete. In particular, while we generally verify the robustness of the five broad theories that they have highlighted as being important for explaining spatial mobility, we find that the specific determinants within

each of these theories that are important are sensitive to the choice of the particular measure 
of spatial mobility. More importantly, we also find evidence that other theories, above and beyond the five identified by Chetty, Hendren, Kline, and Saez (2014), such as local labor market conditions and state fiscal policies also play important roles in explaining the spatial variation in intergenerational mobility. Finally, our results show substantial evidence of heterogeneity in the effect of mobility determinants on outcomes, which suggests the need for future work to investigate the presence of nonlinearities in the spatial mobility process. 
Figure 1: Model Size Distribution and Posterior Model Probabilities

The red line denotes the prior model size distribution while the blue line denotes the posterior model size distribution.

Posterior Model Size Distribution Mean: 14.1695

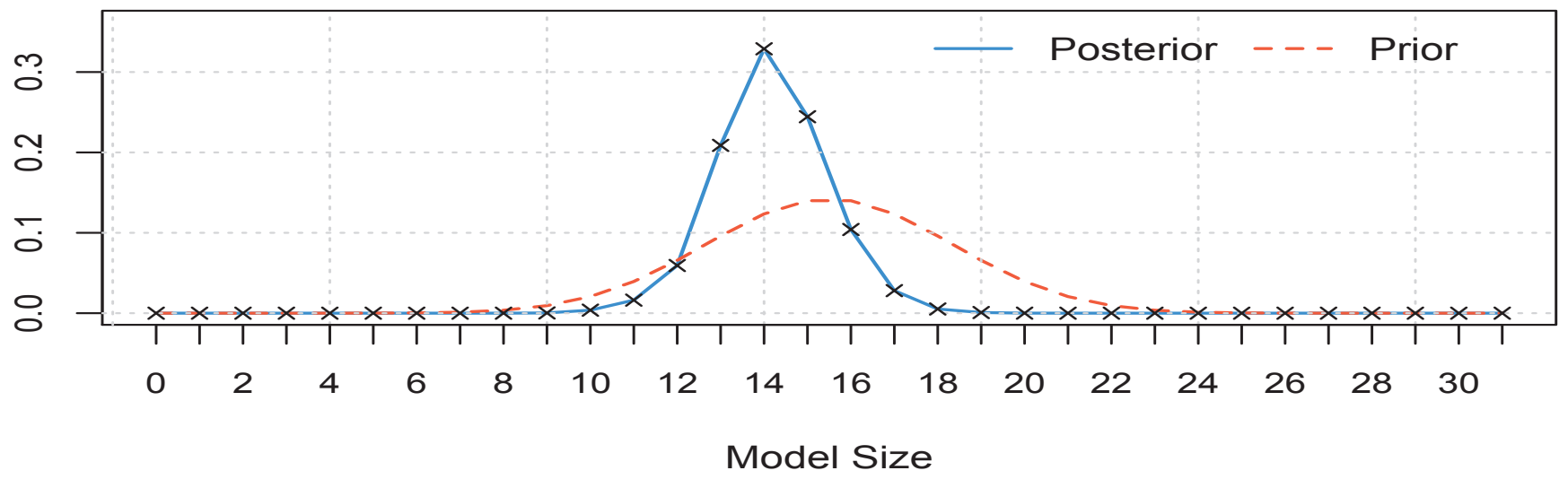

Posterior Model Probabilities (Corr: 0.9995)

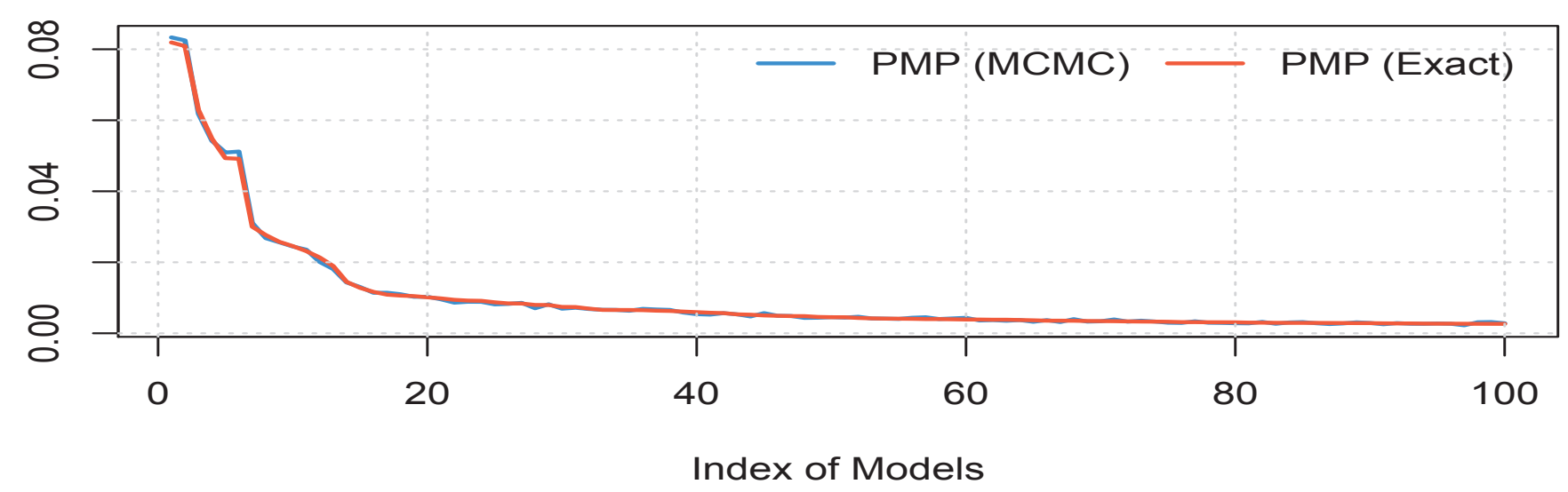


Figure 2: Regressors Included in Best Models

The blue color corresponds to a positive coefficient, red to a negative coefficient, and white to non-inclusion (a zero coefficient). On the horizontal axis it shows the best 100 models, scaled by their PMPs. The intercept and the time trend are always kept in the model.

Model Inclusion Based on Best 100 Models

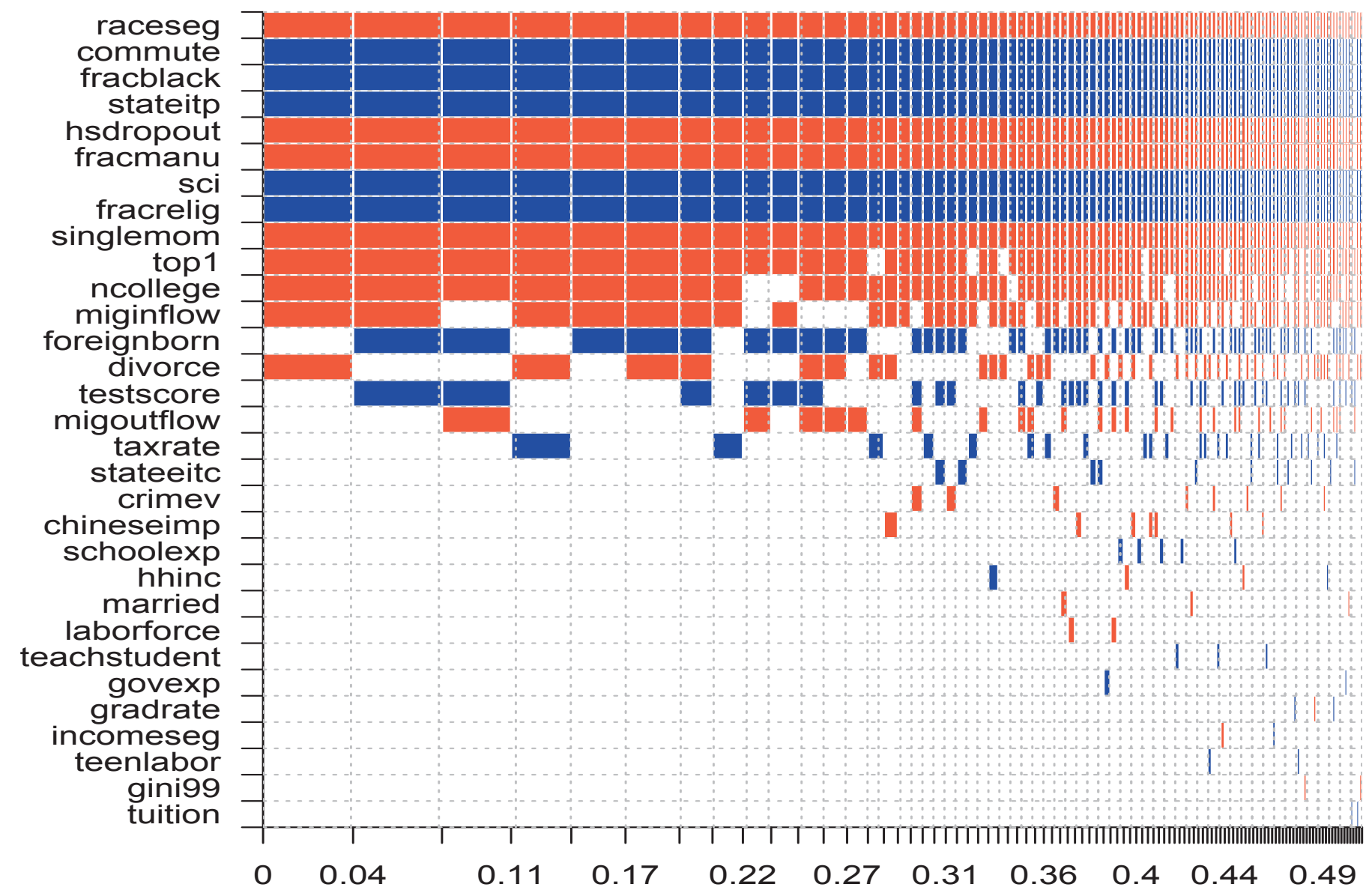

Cumulative Model Probabilities 


\section{Table 1: Descriptive Statistics}

This table reports descriptive statistics for two measures of spatial intergenerational mobility and 31 determinants across US commuting zones made available by the Equality of Opportunity Project. The statistics refer to a balanced sample of 509 commuting zones, which is a sub-sample of the one used by Chetty, Hendren, Kline, and Saez (2014).

Variable

Absolute Upward Mobility

Relative Mobility

\section{Segregation}

Fraction of Black Residents

Racial Segregation Theil Index

Income Segregation Theil Index

Share with Commute $<15$ Mins

Income Distribution

Household Income per Capita for Working-Age Adults

Top 1\% Income Share for Parents

Gini Bottom 99\%

Tax

Local Tax Rate

Local Government Expenditures per Capita

State EITC Exposure

State Income Tax Progressivity

K-12 Education

School Expenditure per Student

Teacher-Student Ratio

Test Score Percentile

High School Dropout Rate

College

Number of Colleges per Capita

Mean College Tuition

College Graduation Rate

Local Labor Market

Labor Force Participation Rate

Fraction Working in Manufacturing

Growth in Chinese Imports 1990-2000

Teenage Labor Force Participation Rate

Migration

Migration Inflow Rate

Migration Outflow Rate

Fraction of Foreign Born Residents

Social Capital

Social Capital Index

Fraction Religious

Violent Crime Rate

Family Structure

Fraction of Children with Single Mothers

Fraction of Adults Divorces

Fraction of Adults Married

\begin{tabular}{|c|c|c|c|}
\hline $\begin{array}{l}\text { Mean } \\
43.259\end{array}$ & $\begin{array}{r}\text { Std. Dev. } \\
5.182\end{array}$ & $\begin{array}{r}\text { Min } \\
26.672\end{array}$ & $\begin{array}{r}\text { Max } \\
64.019\end{array}$ \\
\hline 0.331 & 0.061 & 0.121 & 0.488 \\
\hline 0.090 & 0.131 & 0.001 & 0.6 \\
\hline 0.147 & 0.097 & 0.006 & 0.5 \\
\hline 0.047 & 0.031 & 0.003 & 0.1 \\
\hline 0.426 & 0.119 & 0.156 & 0.7 \\
\hline 2728.980 & 5342.714 & 17400.510 & 54014.1 \\
\hline 11.165 & 4.170 & 4.291 & 55.8 \\
\hline 0.307 & 0.055 & 0.175 & 0.4 \\
\hline 0.019 & 0.007 & 0.007 & 0.0 \\
\hline 189.219 & 655.833 & 992.257 & 5441.6 \\
\hline 1.474 & 4.008 & 0.000 & 21.3 \\
\hline 0.839 & 1.509 & 0.000 & 6.3 \\
\hline 5.952 & 1.071 & 4.086 & 11.9 \\
\hline 16.918 & 2.132 & 10.685 & 24.8 \\
\hline-0.692 & 7.790 & -30.399 & 17.4 \\
\hline 0.001 & 0.018 & -0.034 & 0.0 \\
\hline 0.023 & 0.020 & 0.004 & 0.2 \\
\hline 1247.333 & 3738.171 & 0.000 & 24619.0 \\
\hline-0.005 & 0.131 & -0.350 & 0.4 \\
\hline 0.620 & 0.056 & 0.417 & 0.78 \\
\hline 0.154 & 0.076 & 0.009 & 0.4 \\
\hline 1.257 & 1.714 & 0.000 & 25.4 \\
\hline 0.005 & 0.001 & 0.002 & 0.0 \\
\hline 0.017 & 0.010 & 0.003 & 0.07 \\
\hline 0.017 & 0.007 & 0.004 & 0.0 \\
\hline 0.042 & 0.049 & 0.004 & 0.3 \\
\hline 0.022 & 1.127 & -3.199 & 3.07 \\
\hline 0.533 & 0.146 & 0.214 & 1.0 \\
\hline 0.002 & 0.001 & 0.000 & 0.0 \\
\hline 0.211 & 0.050 & 0.082 & 0.4 \\
\hline 0.098 & 0.015 & 0.042 & 0.1 \\
\hline 0.566 & 0.041 & 0.373 & 0.6 \\
\hline
\end{tabular}




\section{Table 2: Univariate Regressions}

This table reports the regression coefficients and their corresponding standard errors from univariate LS regressions of a measure of mobility on the variable listed in each row. These results replicate Table VII in Chetty, Hendren, Kline, and Saez (2014) using a balanced sub-sample, instead. Both the dependent and independent variables are ( denote significance of the regression coefficients at $1 \%, 5 \%$, and $10 \%$, respectively.

Absolute Upward Mobility

Relative Mobility

\begin{tabular}{|c|c|c|c|c|c|c|c|c|c|c|c|}
\hline \multicolumn{2}{|c|}{ Baseline } & \multicolumn{2}{|c|}{ State F.E. } & \multicolumn{2}{|c|}{ Pop. Weighted } & \multicolumn{2}{|c|}{ Urban Areas Only } & \multicolumn{2}{|c|}{ Controls } & \multirow[b]{2}{*}{ COEF } & \multirow[b]{2}{*}{$\mathrm{SE}$} \\
\hline COEF & $\mathrm{SE}$ & COEF & SE & COEF & $\mathrm{SE}$ & COEF & $\mathrm{SE}$ & COEF & SE & & \\
\hline$-0.534^{* * *}$ & 0.026 & $-0.360^{* * *}$ & 0.031 & $-0.534^{* * *}$ & 0.026 & $-0.695^{* * *}$ & 0.038 & $-0.396^{* * *}$ & 0.025 & $0.580^{* * *}$ & 0.026 \\
\hline-0.331 & 0.042 & $-0.287^{* * *}$ & 0.038 & $-0.331 * * *$ & 0.042 & $-0.413^{* * *}$ & 0.050 & $-0.173^{* * *}$ & 0.029 & $0.387^{* * *}$ & 0.037 \\
\hline$-0.296^{* * *}$ & 0.037 & $-0.248^{* * *}$ & 0.025 & $-0.296 * * *$ & 0.037 & $-0.219^{* * *}$ & 0.059 & $-0.129^{* * *}$ & 0.026 & $0.112^{* * *}$ & 0.041 \\
\hline $0.706^{* * *}$ & 0.040 & $0.478^{* * *}$ & 0.039 & $0.706^{* * *}$ & 0.040 & $0.575 * * *$ & 0.058 & $0.436^{* * *}$ & 0.037 & $-0.511^{* * *}$ & 0.048 \\
\hline $0.075^{*}$ & 0.040 & -0.012 & 0.058 & $0.075^{*}$ & 0.040 & 0.034 & 0.059 & 0.040 & 0.038 & $-0.124 * * *$ & 0.046 \\
\hline$-0.604^{* * *}$ & 0.034 & $-0.481^{* * *}$ & 0.050 & $-0.604^{* * *}$ & 0.034 & $-0.611^{* * *}$ & 0.055 & $-0.396^{* * *}$ & 0.038 & $0.452^{* * *}$ & 0.040 \\
\hline$-0.228^{* * *}$ & 0.061 & $-0.093^{*}$ & 0.053 & $-0.228^{* * *}$ & 0.061 & $-0.123^{* *}$ & 0.059 & $-0.094 * * *$ & 0.031 & 0.035 & 0.056 \\
\hline $0.378^{* * *}$ & 0.036 & $0.181^{* * *}$ & 0.051 & $0.378^{* * *}$ & 0.036 & $0.233^{* * *}$ & 0.046 & $0.156^{* * *}$ & 0.036 & $-0.418^{* * *}$ & 0.045 \\
\hline $0.246^{* * *}$ & 0.050 & 0.043 & 0.056 & $0.246^{* * *}$ & 0.050 & $0.096^{* *}$ & 0.048 & $0.084^{* *}$ & 0.041 & $-0.437 * * *$ & 0.053 \\
\hline $0.231^{* * *}$ & 0.032 & 0.098 & 0.063 & $0.231^{* * *}$ & 0.032 & $0.321 * * *$ & 0.058 & $0.103^{* * *}$ & 0.029 & $-0.131 * * *$ & 0.028 \\
\hline $0.163^{* * *}$ & 0.040 & 0.087 & 0.065 & $0.163^{* * *}$ & 0.040 & $0.165^{* * *}$ & 0.047 & $0.068^{* *}$ & 0.029 & $-0.147^{* * *}$ & 0.039 \\
\hline $0.214^{* * *}$ & 0.038 & $-0.007 * *$ & 0.062 & $0.214^{* * *}$ & 0.038 & $0.225^{* * *}$ & 0.055 & 0.005 & 0.030 & $-0.216 * * *$ & 0.044 \\
\hline$-0.212^{* * *}$ & 0.041 & $-0.184^{* * *}$ & 0.067 & $-0.212^{* * *}$ & 0.041 & 0.030 & 0.052 & $-0.106^{* * *}$ & 0.034 & -0.077 & 0.048 \\
\hline $0.572^{* * *}$ & 0.039 & $0.537^{* * *}$ & 0.046 & $0.572^{* * *}$ & 0.039 & $0.428^{* * *}$ & 0.060 & $0.318^{* * *}$ & 0.049 & $-0.358^{* * *}$ & 0.052 \\
\hline$-0.557 * * *$ & 0.048 & $-0.392^{* * *}$ & 0.053 & $-0.567^{* * *}$ & 0.048 & $-0.485^{* * *}$ & 0.062 & $-0.324^{* * *}$ & 0.042 & $0.357 * * *$ & 0.045 \\
\hline $0.226^{* *}$ & 0.107 & 0.029 & 0.100 & $0.226^{* *}$ & 0.107 & -0.048 & 0.081 & 0.045 & 0.092 & $-0.125^{*}$ & 0.064 \\
\hline-0.028 & 0.041 & -0.044 & 0.049 & -0.028 & 0.041 & -0.004 & 0.065 & -0.030 & 0.035 & $0.111^{* * *}$ & 0.038 \\
\hline $0.152^{* * *}$ & 0.041 & $0.141^{* * *}$ & 0.034 & $0.152^{* * *}$ & 0.041 & $0.186^{* *}$ & 0.067 & $0.130^{* * *}$ & 0.031 & -0.042 & 0.041 \\
\hline $0.267^{* * *}$ & 0.039 & $0.081 *$ & 0.042 & $0.267^{* * *}$ & 0.039 & $0.225 * * *$ & 0.069 & $0.147^{* * *}$ & 0.030 & $-0.274^{* * *}$ & 0.046 \\
\hline$-0.258^{* * *}$ & 0.042 & 0.037 & 0.049 & $-0.258^{* * *}$ & 0.042 & $-0.162^{* *}$ & 0.061 & 0.048 & 0.038 & $0.421^{* * *}$ & 0.043 \\
\hline$-0.156^{* *}$ & 0.062 & 0.004 & 0.023 & $-0.156^{* *}$ & 0.062 & -0.054 & 0.076 & $-0.053^{* *}$ & 0.022 & $0.154^{* *}$ & 0.086 \\
\hline $0.624^{* * *}$ & 0.034 & $0.476^{* * *}$ & 0.055 & $0.624^{* * *}$ & 0.034 & $0.524 * * *$ & 0.056 & $0.334^{* * *}$ & 0.036 & $-0.529 * * *$ & 0.040 \\
\hline$-0.142^{* * *}$ & 0.041 & $-0.174^{* * *}$ & 0.038 & $-0.142^{* * *}$ & 0.041 & -0.015 & 0.059 & $-0.163^{* * *}$ & 0.030 & $-0.195 * * *$ & 0.038 \\
\hline$-0.063^{* * *}$ & 0.037 & $-0.136^{* * *}$ & 0.037 & $-0.063^{*}$ & 0.037 & 0.001 & 0.056 & $-0.062 * *$ & 0.030 & $-0.204^{* * *}$ & 0.039 \\
\hline 0.022 & 0.028 & $-0.062^{*}$ & 0.033 & 0.022 & 0.028 & $0.100^{* * *}$ & 0.036 & 0.001 & 0.021 & $-0.290^{* * *}$ & 0.034 \\
\hline $0.635^{* * *}$ & 0.036 & $0.472^{* * *}$ & 0.059 & $0.636^{* * *}$ & 0.036 & $0.506^{* * *}$ & 0.057 & $0.381^{* * *}$ & 0.037 & $-0.336^{* * *}$ & 0.045 \\
\hline $0.465^{* * *}$ & 0.043 & $0.338^{* * *}$ & 0.045 & $0.465^{* * *}$ & 0.043 & $0.422 * * *$ & 0.060 & $0.323^{* * *}$ & 0.031 & $-0.090^{*}$ & 0.050 \\
\hline$-0.559^{* * *}$ & 0.059 & $-0.321 * * *$ & 0.045 & $-0.559^{* * *}$ & 0.059 & $-0.382^{* * *}$ & 0.066 & $-0.213^{* * *}$ & 0.041 & $0.377^{* * *}$ & 0.070 \\
\hline$-0.697^{* * *}$ & 0.033 & $-0.563^{* * *}$ & 0.043 & $-0.697^{* * *}$ & 0.033 & $-0.754^{* * *}$ & 0.042 & $-0.639^{* * *}$ & 0.057 & $0.618^{* * *}$ & 0.032 \\
\hline$-0.440^{* * *}$ & 0.046 & $-0.376^{* * *}$ & 0.046 & $-0.440^{* * *}$ & 0.046 & $-0.340^{* * *}$ & 0.063 & $-0.424^{* * *}$ & 0.033 & $0.154^{* * *}$ & 0.052 \\
\hline $0.492^{* * *}$ & 0.041 & $0.384^{* * *}$ & 0.049 & $0.492^{* * *}$ & 0.041 & $0.433^{* * *}$ & 0.057 & $0.221^{* * *}$ & 0.063 & $-0.334^{* * *}$ & 0.051 \\
\hline
\end{tabular}

Segregation

Fraction of Black Residents

Racial Segregation Theil Index

Income Segregation Theil Index

Share with Commute $<15$ Mins

Income Distribution

Household Income per Capita for Working-Age Adults

Gini Bottom $99 \%$

Top $1 \%$ Income Share for Parents

Tax

Local Tax Rate

Local Government Expenditures per Capita

State Income Tax Progressivity

\section{K-12 Education}

School Expenditure per Student

Teacher-Student Ratio

High School Dropout Rate

\section{College}

Number of Colleges per Capita

Mean College Tuition

\section{Local Labor Market}

Labor Force Participation Rate

Fraction Working in Manufacturing

Growth in Chinese Inports

\section{Migration}

Migration Inflow Rate

Migration Outflow Rate

Fraction of Foreign Born Residents

\section{Social Capital}

Social Capital Index

Fraction Religious

Violent Crime Rate

Family Structure

Fraction of Children with Single Mothers

Fraction of Adults Divorces

$\begin{array}{lllllllll}0.492 * * * & 0.041 & 0.384 * * * & 0.049 & 0.492 * * * & 0.041 & -0.34 * * * & 0.063 \\ & & & & & 0.433 * * * & 0.057\end{array}$

$0.221 * * * \quad 0.063-0.334^{* * *} \quad 0.051$ 


\section{Table 3: Short Regressions}

This table reports the regression coefficients and their corresponding standard errors from multivariate LS regressions of a measure of mobility on a set of determinants. These results replicate Table IX in Chetty, Hendren, Kline, and Saez (2014) using a balanced sub-sample, instead. Both the dependent and independent variables are standardized to have mean 0 and standard deviation 1 in the estimation so that the regression coefficient equal correlation coefficients. ***, **, and * denote significance of the regression coefficient at $1 \%$, $5 \%$, and $10 \%$, respectively.

Racial Segregation Theil Index

Gini Bottom 99\%

High School Dropout Rate

Social Capital Index

Fraction of Children with Single Mothers
(1)

(2)

$$
\begin{aligned}
& -0.100^{* * *} \\
& (0.028)
\end{aligned}
$$

0.015

(0.041)

$-0.162^{* * *}$
$(0.037)$

$0.323^{* * *}$

(0.032)

$-0.444^{* * *}$

(0.039)
(3)

$-0.118^{* * *}$

$(0.030)$

$-0.097^{* * *}$

(0.028)

$-0.038$

0.012

(0.041)

. $129 * *$

$-0.129 * * *$
$(0.045)$

(0.037)

$0.221^{* * *}$

$0.319^{* * *}$

(0.032)

$-0.389 * * *$

(0.048)

-0.438
$(0.039)$

(1)
$-0.183^{* * *}$

(4)

$-0.157^{* * *}$

(0.039)

\subsection{6}

$-0.134^{* *}$

(0.052)

$0.269 * * *$

$-0.552^{* *}$

Fraction Black Residents

Constant

$$
\begin{gathered}
-0.021 \\
(0.024)
\end{gathered}
$$

\subsection{1}

(0.110)

$-0.023$

(0.023)

0.024$$
\mathrm{X}
$$

Population Weighted

Urban Areas Only

Adjusted R-squared

Sample Size

$$
\mathrm{x}
$$

$\begin{array}{ll}0.672 & 0.799 \\ 509 & 509\end{array}$

$\mathrm{x}$

0.677

509

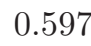

0.314

509
(0.068)

(0.050)

(0.061)

(0.053)

(0.038)

$-0.006$

(0.032)

0.011

(0.035)

(0.027)

(6)

(7)

$.170 * * *$

$0.031)$

(0.038) (0.031)

(0.063) (0.040)

$0.111^{* * *}-0.245^{* * *}$

(0.043) (0.037)

$0.025 \quad 0.326^{* * *}$

(0.063) (0.039)

$-0.660 * * *$

(0.053)

$-0.042$

(0.043)

$-0.036$

(0.028) 278
0.571

509

0.555 


\section{Table 4: BMA Regressions - Posterior Model Probabilities}

Pasility on the model space spanned by the various subsets of determinants. Each cell reports the posterior inclusion probability (PIP), which is the sum of posterior model probabilities over all those models that contain that variable, using the Benchmark Priors (g-BRIC).

\begin{tabular}{|c|c|c|c|c|c|c|}
\hline & \multicolumn{5}{|c|}{ Absolute Upward Mobility } & \multirow{2}{*}{$\begin{array}{l}\text { Relative } \\
\text { Mobility }\end{array}$} \\
\hline & Baseline & State F.E. & $\begin{array}{l}\text { Pop. } \\
\text { Weighted }\end{array}$ & $\begin{array}{l}\text { Urban } \\
\text { Areas } \\
\text { Only } \\
\end{array}$ & Controls & \\
\hline \multicolumn{7}{|l|}{ Segregation } \\
\hline Fraction of Black Residents & 0.985 & 1.000 & - & - & 0.988 & - \\
\hline Racial Segregation Theil Index & 0.989 & 1.000 & 1.000 & 0.198 & 0.995 & 1.000 \\
\hline Income Segregation Theil Index & 0.038 & 0.071 & 0.056 & 0.301 & 0.043 & 0.036 \\
\hline Share with Commute $<15$ Mins & 1.000 & 1.000 & - & - & 1.000 & - \\
\hline \multicolumn{7}{|l|}{ Income Distribution } \\
\hline Household Income per Capita for Working-Age Adults & 0.061 & 0.045 & 1.000 & 0.999 & 0.057 & 1.000 \\
\hline Gini Bottom $99 \%$ & 0.037 & 0.047 & 0.299 & 0.769 & 0.040 & 0.046 \\
\hline Top $1 \%$ Income Share for Parents & 0.841 & 0.990 & 0.053 & 0.068 & 0.978 & 0.036 \\
\hline \multicolumn{7}{|l|}{ Tax } \\
\hline Local Tax Rate & 0.250 & 0.108 & 0.531 & 0.391 & 0.049 & 0.035 \\
\hline Local Government Expenditures per Capita & 0.043 & 0.053 & 0.573 & 0.636 & 0.034 & 0.041 \\
\hline State EITC Exposure & 0.098 & 0.053 & 0.084 & 0.049 & 0.036 & 0.034 \\
\hline State Income Tax Progressivity & 1.000 & 1.000 & 0.050 & 0.479 & 0.999 & 0.112 \\
\hline \multicolumn{7}{|l|}{ K-12 Education } \\
\hline School Expenditure per Student & 0.072 & 0.041 & 1.000 & 0.450 & 0.034 & 0.113 \\
\hline Teacher-Student Ratio & 0.058 & 0.049 & 0.040 & 0.055 & 0.048 & 0.117 \\
\hline Test Score Percentile & 0.398 & 1.000 & 0.114 & 0.182 & 0.274 & 1.000 \\
\hline High School Dropout Rate & 0.992 & 0.052 & 0.092 & 0.084 & 0.943 & 0.037 \\
\hline \multicolumn{7}{|l|}{ College } \\
\hline Number of Colleges per Capita & 0.831 & 0.920 & 0.997 & 0.303 & 0.993 & 0.038 \\
\hline Mean College Tuition & 0.033 & 0.052 & 0.953 & 0.953 & 0.030 & 0.043 \\
\hline College Graduation Rate & 0.037 & 0.052 & 0.036 & 0.036 & 0.041 & 0.057 \\
\hline \multicolumn{7}{|l|}{ Local Labor Market } \\
\hline Labor Force Participation Rate & 0.059 & 0.052 & 0.043 & 0.045 & 0.056 & 0.034 \\
\hline Fraction Working in Manufacturing & 1.000 & 1.000 & 0.057 & 0.312 & 1.000 & 0.034 \\
\hline Growth in Chinese Imports 1990-2000 & 0.101 & 0.056 & 1.000 & 1.000 & 0.099 & 1.000 \\
\hline Teenage Labor Force Participation Rate & 0.044 & 0.041 & 0.229 & 0.037 & 0.036 & 0.115 \\
\hline \multicolumn{7}{|l|}{ Migration } \\
\hline Migration Inflow Rate & 0.699 & 0.175 & 0.055 & 0.051 & 0.780 & 1.000 \\
\hline Migration Outflow Rate & 0.302 & 0.964 & 0.850 & 0.563 & 0.275 & 0.040 \\
\hline Fraction of Foreign Born Residents & 0.609 & 0.991 & 0.075 & 0.431 & 0.959 & 0.043 \\
\hline \multicolumn{7}{|l|}{ Social Capital } \\
\hline Social Capital Index & 0.995 & 0.050 & 0.183 & 0.726 & 0.991 & 1.000 \\
\hline Fraction Religious & 1.000 & $\begin{array}{l}0.999 \\
0.040\end{array}$ & $\begin{array}{l}0.994 \\
1.000\end{array}$ & 0.481 & $\begin{array}{l}1.000 \\
0.077\end{array}$ & $\begin{array}{l}0.820 \\
0.092\end{array}$ \\
\hline Violent Crime Rate & 0.095 & 0.040 & 1.000 & 1.000 & 0.077 & 0.092 \\
\hline \multicolumn{7}{|l|}{ Family Structure } \\
\hline Fraction of Children with Single Mothers & 1.000 & 1.000 & 0.045 & 0.044 & 1.000 & 0.122 \\
\hline Fraction of Adults Divorced & 0.453 & 0.066 & 1.000 & 1.000 & 0.754 & 1.000 \\
\hline Fraction of Adults Married & 0.051 & 0.045 & 1.000 & 0.352 & 0.063 & 0.037 \\
\hline State Fixed Effects & no & yes & no & no & no & no \\
\hline Controls & no & no & no & no & yes & no \\
\hline
\end{tabular}


Table 5: BMA Regressions - Posterior Means and Standard Errors

This table reports the posterior mean (PM) and the posterior standard error (PSE) for BMA regressions of a measure of mobility on the model space spanned by the various unsets of dor model probability and the PSE is the BMA estimate for the standard error (SE). ***, **, and * denote significance of the regression coefficient at $1 \%, 5 \%$, and $10 \%$, respectively.

Absolute Upward Mobility

Relative Mobility

\begin{tabular}{|c|c|c|c|c|c|c|c|c|c|c|c|}
\hline \multicolumn{10}{|c|}{ Absolute Upward Mobility } & \multicolumn{2}{|c|}{ Relative Mobility } \\
\hline \multicolumn{2}{|c|}{ Baseline } & \multicolumn{2}{|c|}{ State F.E. } & \multicolumn{2}{|c|}{ Pop. Weighted } & \multicolumn{2}{|c|}{ Urban Areas Only } & \multicolumn{2}{|c|}{ Controls } & \multirow[b]{2}{*}{ COEF } & \multirow[b]{2}{*}{ SE } \\
\hline COEF & $\mathrm{SE}$ & COEF & $\mathrm{SE}$ & COEF & $\mathrm{SE}$ & COEF & $\mathrm{SE}$ & COEF & $\mathrm{SE}$ & & \\
\hline $0.158^{* * *}$ & 0.046 & $0.275^{* * *}$ & 0.033 & - & - & - & - & $-0.152^{* * *}$ & 0.043 & - & - \\
\hline$-0.078^{* * *}$ & 0.021 & $-0.082^{* * *}$ & 0.017 & $-0.096 * * *$ & 0.020 & -0.015 & 0.035 & $-0.080^{* * *}$ & 0.020 & $0.155^{* * *}$ & 0.017 \\
\hline 0.000 & 0.006 & -0.002 & 0.009 & 0.002 & 0.009 & -0.036 & 0.063 & 0.001 & 0.008 & -0.001 & 0.015 \\
\hline $0.270^{* * *}$ & 0.034 & $0.292^{* * *}$ & 0.029 & - & - & - & - & $0.260 * * *$ & 0.032 & - & - \\
\hline 0.001 & 0.012 & 0.000 & 0.006 & $0.225^{* * *}$ & 0.035 & $0.256^{* * *}$ & 0.055 & 0.002 & 0.014 & $-0.093^{* * *}$ & 0.019 \\
\hline 0.000 & 0.005 & 0.000 & 0.005 & -0.023 & 0.040 & -0.162 & 0.108 & -0.001 & 0.005 & 0.002 & 0.014 \\
\hline-0.087 & 0.048 & $-0.127^{* * *}$ & 0.033 & -0.001 & 0.010 & -0.003 & 0.029 & $-0.111^{* * *}$ & 0.034 & 0.000 & 0.006 \\
\hline 0.014 & 0.027 & 0.004 & 0.014 & 0.055 & 0.059 & 0.061 & 0.086 & 0.001 & 0.007 & -0.001 & 0.008 \\
\hline 0.001 & 0.007 & 0.001 & 0.008 & 0.036 & 0.036 & 0.059 & 0.052 & 0.000 & 0.006 & -0.007 & 0.060 \\
\hline 0.003 & 0.010 & 0.001 & 0.006 & 0.003 & 0.014 & -0.001 & 0.010 & 0.000 & 0.004 & 0.000 & 0.000 \\
\hline $0.101^{* * *}$ & 0.017 & $0.168^{* * *}$ & 0.020 & 0.001 & 0.005 & 0.039 & 0.046 & $0.074 * * *$ & 0.017 & 0.000 & 0.000 \\
\hline 0.002 & 0.010 & 0.000 & 0.005 & $0.095^{* * *}$ & 0.017 & 0.038 & 0.048 & 0.000 & 0.004 & 0.000 & 0.001 \\
\hline 0.001 & 0.009 & 0.001 & 0.008 & 0.000 & 0.005 & 0.001 & 0.013 & 0.001 & 0.007 & 0.000 & 0.001 \\
\hline 0.028 & 0.039 & $0.193^{* * *}$ & 0.028 & 0.004 & 0.014 & 0.016 & 0.039 & 0.016 & 0.029 & $-0.005^{* * *}$ & 0.001 \\
\hline$-0.090^{* * *}$ & 0.024 & -0.001 & 0.006 & 0.004 & 0.015 & -0.005 & 0.023 & $-0.070 * * *$ & 0.027 & 0.000 & 0.000 \\
\hline-0.058 & 0.033 & $-0.058^{* *}$ & 0.025 & $-0.094 * * *$ & 0.023 & -0.023 & 0.040 & $-0.087 * * *$ & 0.022 & 0.002 & 0.021 \\
\hline 0.000 & 0.003 & -0.001 & 0.005 & $-0.075^{* * *}$ & 0.027 & $-0.116^{* * *}$ & 0.041 & 0.000 & 0.003 & -0.003 & 0.023 \\
\hline 0.000 & 0.004 & -0.001 & 0.005 & 0.000 & 0.004 & 0.000 & 0.007 & 0.001 & 0.005 & 0.000 & 0.000 \\
\hline-0.002 & 0.010 & -0.001 & 0.006 & -0.001 & 0.005 & 0.001 & 0.008 & -0.002 & 0.009 & 0.000 & 0.002 \\
\hline$-0.236^{* * *}$ & 0.025 & $-0.182^{* * *}$ & 0.021 & 0.001 & 0.008 & -0.032 & 0.055 & $-0.167^{* * *}$ & 0.024 & 0.000 & 0.007 \\
\hline-0.003 & 0.010 & -0.001 & 0.005 & $-0.214^{* * *}$ & 0.026 & $-0.361^{* * *}$ & 0.042 & -0.003 & 0.010 & $0.227^{* * *}$ & 0.022 \\
\hline 0.001 & 0.010 & 0.000 & 0.007 & -0.009 & 0.018 & 0.000 & 0.007 & -0.001 & 0.007 & 0.000 & 0.001 \\
\hline-0.055 & 0.041 & -0.011 & 0.028 & 0.002 & 0.012 & -0.001 & 0.015 & -0.071 & 0.043 & $-12.263^{* * *}$ & 2.355 \\
\hline-0.021 & 0.036 & $-0.107^{* * *}$ & 0.030 & $-0.062 *$ & 0.033 & -0.086 & 0.086 & -0.021 & 0.037 & 0.003 & 0.047 \\
\hline 0.044 & 0.041 & $0.100^{* * *}$ & 0.025 & -0.002 & 0.011 & -0.061 & 0.078 & $0.081 * * *$ & 0.029 & -0.006 & 0.060 \\
\hline $0.141 * * *$ & 0.036 & 0.001 & 0.008 & 0.009 & 0.021 & 0.117 & 0.087 & $0.137^{* * *}$ & 0.033 & $-0.253^{* * *}$ & 0.039 \\
\hline $0.164^{* * *}$ & 0.022 & $0.097 * * *$ & 0.022 & $0.138^{* * *}$ & 0.035 & 0.083 & 0.101 & $0.140^{* * *}$ & 0.021 & $0.006 * *$ & 0.003 \\
\hline-0.004 & 0.016 & 0.000 & 0.006 & $0.160^{* * *}$ & 0.022 & $0.226 * * *$ & 0.033 & -0.003 & 0.013 & 0.002 & 0.006 \\
\hline$-0.467^{* * *}$ & 0.049 & $-0.462 * * *$ & 0.039 & -0.001 & 0.008 & -0.001 & 0.009 & $-0.419^{* * *}$ & 0.045 & 0.376 & 1.201 \\
\hline-0.032 & 0.039 & -0.002 & 0.009 & $-0.336^{* * *}$ & 0.036 & $-0.428^{* * *}$ & 0.074 & -0.057 & 0.040 & $0.447^{* * *}$ & 0.043 \\
\hline-0.001 & 0.010 & 0.000 & 0.006 & $-0.118^{* * *}$ & 0.022 & -0.028 & 0.043 & -0.002 & 0.012 & -0.002 & 0.022 \\
\hline no & & yes & & no & & $\mathrm{n}$ & & no & & no & \\
\hline
\end{tabular}

Segregation

Fraction of Black Residents

Racial Segregation Theil Index

Shame Segregation Theil Index

Income Distribution

(

Capita for Working-Age Adults

Gini Bottom 99\%

Tax

Local Tax Rate

Local Government Expenditures per Capita

State EITC Exposure

State Income Tax Progressivity

K-12 Education

School Expenditure per Student

Teacher-Student Ratio

High School Dror

\section{College}

Number of Colleges per Capita

Mean College Tuition

College Graduation Rate

Local Labor Market

Labor Force Participation Rate

Fraction Working in Manufacturing

Teenage Labor Force Participation Rat

Migration

Migration Inflow Rate

Migration Outflow Rate

Fraction of Foreign Born Residents

\section{Social Capital}

Social Capital Index

Fraction Religious

Violent Crime Rate

\section{Family Structure}

Fraction of Children with Single Mothers

Fraction of Adults Divorced
Fraction of Adults Married

State Fixed Effects

Controls 
Table 6: BMA Regressions - Posterior Mode Models

This table reports the posterior mode models in the BMA regressions of a measure of mobility on the model space spanned by the various subsets of determinants and using the Benchmark Priors (g-BRIC). ${ }^{* * *}, * *$, and $*$ denote significance of the regression coefficient at $1 \%, 5 \%$, and $10 \%$, respectively.

Absolute Upward Mobility

Relative Mobility

\begin{tabular}{|c|c|c|c|c|c|c|c|c|c|c|c|}
\hline \multicolumn{10}{|c|}{ Absolute Upward Mobility } & \multicolumn{2}{|c|}{ Relative Mobility } \\
\hline \multicolumn{2}{|c|}{ Baseline } & \multicolumn{2}{|c|}{ State F.E. } & \multicolumn{2}{|c|}{ Pop. Weighted } & \multicolumn{2}{|c|}{ Urban Areas Only } & \multicolumn{2}{|c|}{ Controls } & \multirow[b]{2}{*}{ COEF } & \multirow[b]{2}{*}{ SE } \\
\hline COEF & SE & COEF & SE & COEF & SE & COEF & SE & COEF & SE & & \\
\hline $0.113^{* * *}$ & 0.043 & $0.290 * * *$ & 0.036 & - & - & - & - & $0.105^{* * *}$ & 0.043 & - & - \\
\hline $\begin{array}{l}-0.078^{* * *} \\
-\end{array}$ & 0.027 & $-0.079 * * *$ & 0.024 & $-0.231 * * *$ & 0.032 & - & - & $-0.073^{* * *}$ & 0.025 & 0.328 & 0.044 \\
\hline $0.271 * * *$ & $\overline{0} 0.041$ & $\overline{0} 321^{* * *}$ & $\overline{0} 0.035$ & $\begin{array}{l}- \\
-\end{array}$ & - & - & $\begin{array}{c}- \\
-\end{array}$ & $\overline{0} .258^{* * *}$ & $\overline{0} .038$ & $\begin{array}{l}- \\
-\end{array}$ & $\begin{array}{l}- \\
-\end{array}$ \\
\hline - & - & - & - & $0.129^{* * *}$ & 0.034 & $-0.195^{* *}$ & 0.095 & - & - & -0.039 & 0.056 \\
\hline - & - & - & - & - & - & $-0.455^{* * *}$ & 0.069 & - & - & - & - \\
\hline 0.000 & 0.033 & -0.003 & 0.027 & - & - & - & - & 0.006 & 0.034 & - & - \\
\hline - & - & - & - & $0.120^{* * *}$ & 0.036 & - & - & - & - & - & - \\
\hline - & - & - & - & $0.100^{* * *}$ & 0.038 & $0.118^{* * *}$ & 0.050 & - & - & - & - \\
\hline- & - & - & - & - & - & - & - & - & - & - & - \\
\hline $0.102^{* * *}$ & 0.016 & $0.167^{* * *}$ & 0.025 & - & - & - & - & $0.088^{* * *}$ & 0.015 & - & - \\
\hline - & - & - & - & $0.056^{*}$ & 0.033 & 0.020 & 0.060 & & & - & - \\
\hline - & - & - & - & - & - & - & - & - & - & - & - \\
\hline - & - & $0.191 * * *$ & 0.034 & - & - & - & - & - & - & -0.073 & 0.060 \\
\hline$-0.090^{* * *}$ & 0.027 & - & - & - & - & - & - & $-0.080^{* * *}$ & 0.025 & - & - \\
\hline \multirow{3}{*}{$\begin{array}{l}-0.073^{* * *} \\
- \\
-\end{array}$} & 0.024 & $-0.054 * * *$ & 0.021 & $0.108^{* *}$ & 0.050 & - & - & $-0.089 * * *$ & 0.023 & - & - \\
\hline & - & - & - & $-0.065^{*}$ & 0.034 & $-0.198 * * *$ & 0.083 & - & - & - & - \\
\hline & - & - & - & - & - & - & - & - & - & - & - \\
\hline \multirow{4}{*}{$\begin{array}{l}- \\
-0.230 * * * \\
- \\
-\end{array}$} & - & - & - & - & - & - & - & - & - & - & - \\
\hline & 0.020 & $-0.157^{* * *}$ & 0.020 & - & - & - & - & $-0.164 * * *$ & 0.021 & - & - \\
\hline & - & - & - & $-0.132^{* * *}$ & 0.037 & $-0.123^{* * *}$ & 0.053 & - & - & $0.140 *$ & 0.074 \\
\hline & - & - & - & - & - & $0.267^{* * *}$ & 0.069 & - & - & - & - \\
\hline \multirow{3}{*}{$\begin{array}{l}-0.062^{* * *} \\
- \\
-\end{array}$} & 0.020 & - & - & - & - & - & - & $-0.066^{* * *}$ & 0.020 & $-0.281^{* * *}$ & 0.043 \\
\hline & - & $-0.103^{* * *}$ & 0.018 & 0.002 & 0.030 & -0.061 & 0.049 & - & - & - & - \\
\hline & - & $0.074^{* *}$ & 0.029 & - & - & - & - & - & - & - & - \\
\hline \multirow{3}{*}{$\begin{array}{l}0.182^{* * *} \\
0.149^{* * *} \\
-\end{array}$} & 0.024 & - & - & - & - & - & - & $0.167^{* * *}$ & 0.023 & $-0.270 * * *$ & 0.053 \\
\hline & 0.021 & $0.106^{* * *}$ & 0.025 & $0.224^{* * *}$ & 0.033 & - & - & $0.129 * * *$ & 0.020 & -0.030 & 0.046 \\
\hline & - & - & - & - & $-0.263^{* * *}$ & 0.045 & -0.061 & 0.054 & - & - & - \\
\hline \multirow{3}{*}{$\begin{array}{l}-0.489^{* * *} \\
-0.078^{* * *} \\
-\end{array}$} & 0.054 & -0.526 & 0.041 & - & & - & - & & - & $-0.457^{* * *}$ & 0.056 \\
\hline & 0.026 & - & - & $-0.260^{* * *}$ & 0.038 & $-0.241^{* * *}$ & 0.047 & $-0.094^{* * *}$ & 0.025 & $0.113^{* *}$ & 0.050 \\
\hline & - & - & - & $0.262^{* * *}$ & 0.040 & - & - & - & - & - & - \\
\hline \multicolumn{2}{|c|}{0.040} & \multicolumn{2}{|c|}{0.299} & \multicolumn{2}{|c|}{0.086} & \multicolumn{2}{|c|}{0.007} & \multicolumn{2}{|c|}{0.199} & \multicolumn{2}{|c|}{0.215} \\
\hline & & yes & & & & $\mathrm{n}$ & & no & & $\mathrm{n}$ & \\
\hline no & & no & & & & $\mathrm{n}$ & & yes & & $\mathrm{n}$ & \\
\hline
\end{tabular}

Segregation

Black Residents

Racial Segregation Theil Index

Share with Commute $<15$ Mins

\section{Income Distribution}

Household Income per Capita for Working-Age Adults Gini Bottom 99\%

Top 1\% Income Share for Parent

Tax

Local Tax Rate

Local Government Expenditures per Capita

TC Exposure

State Income Tax Progressivity

K-12 Education

School Expenditure per Student

Teacher-Student Ratio

High School Dropout

\section{College}

Number of Colleges per Capita

Mean College Tuition

College Graduation Rate

Local Labor Market

Labor Force Participation Rate

Fraction Working in Manufacturing

Teenage Labor Force Participation Rate

\section{Migration}

Migration Inflow Rate

Migration Outflow Rate

Fraction of Foreign Born Residents

\section{Social Capital}

Social Capital Index

Fraction Religious

Violent Crime Rate

\section{Family Structure}

Fraction of Children with Single Mothers

Fraction of Adults Divorced

Fraction of Adults Marrie

Posterior Model Probability

State Fixed Effects

Controls 
Table 7: Long Full Regressions

This table reports the regression coefficients and their corresponding standard errors from multivariate LS regressions of a measure of mobility on the full set of determinants. Both the dependent and independent variables are standardized to have mean 0 and standard deviation 1 in the estimation so that the regression coefficient equal correlation coefficients. ${ }^{* * *}, * *$, and $*$ denote significance of the regression coefficient at $1 \%, 5 \%$, and $10 \%$, respectively.

Absolute Upward Mobility

Relative Mobility

\begin{tabular}{|c|c|c|c|c|c|c|c|c|c|c|c|}
\hline \multicolumn{2}{|c|}{ Baseline } & \multicolumn{2}{|c|}{ State F.E. } & \multicolumn{2}{|c|}{ Pop. Weighted } & \multicolumn{2}{|c|}{ Urban Areas Only } & \multicolumn{2}{|c|}{ Controls } & \multirow[b]{2}{*}{ COEF } & \multirow[b]{2}{*}{ SE } \\
\hline COEF & $\mathrm{SE}$ & COEF & SE & COEF & SE & COEF & SE & COEF & SE & & \\
\hline $0.170^{* * *}$ & 0.048 & $0.228^{* * *}$ & 0.050 & $0.167^{* * *}$ & 0.048 & 0.067 & 0.063 & $0.152^{* * *}$ & 0.049 & $0.154^{* * *}$ & 0.056 \\
\hline$-0.080^{* * *}$ & 0.029 & $-0.086 * * *$ & 0.028 & $-0.079^{* * *}$ & 0.029 & $-0.071 *$ & 0.040 & $-0.083^{* * *}$ & 0.027 & $0.244^{* * *}$ & 0.040 \\
\hline-0.008 & 0.036 & -0.025 & 0.035 & -0.009 & 0.036 & $-0.093^{*}$ & 0.053 & 0.020 & 0.035 & -0.020 & 0.051 \\
\hline $0.262^{* * *}$ & 0.056 & $0.253^{* * *}$ & 0.054 & $0.261 * * *$ & 0.056 & $0.198 * * *$ & 0.060 & $0.279^{* * *}$ & 0.053 & $-0.205^{* * *}$ & 0.069 \\
\hline 0.008 & 0.037 & 0.006 & 0.039 & 0.006 & 0.037 & 0.021 & 0.053 & 0.033 & 0.037 & -0.021 & 0.057 \\
\hline$-0.098 * * *$ & 0.036 & $-0.115^{* * *}$ & 0.037 & $-0.094^{* * *}$ & 0.036 & $-0.198^{* * *}$ & 0.068 & $-0.116^{* * *}$ & 0.034 & -0.026 & 0.063 \\
\hline-0.015 & 0.032 & -0.006 & 0.029 & -0.013 & 0.032 & -0.055 & 0.078 & -0.022 & 0.030 & -0.019 & 0.037 \\
\hline 0.031 & 0.031 & 0.036 & 0.034 & 0.033 & 0.031 & $0.123^{* * *}$ & 0.043 & 0.014 & 0.029 & -0.035 & 0.042 \\
\hline-0.017 & 0.030 & 0.003 & 0.034 & -0.013 & 0.030 & -0.041 & 0.033 & -0.017 & 0.030 & 0.014 & 0.046 \\
\hline 0.021 & 0.020 & 0.015 & 0.028 & 0.019 & 0.020 & 0.060 & 0.037 & 0.010 & 0.020 & -0.038 & 0.029 \\
\hline $0.099^{* * *}$ & 0.021 & $0.156^{* * *}$ & 0.030 & $0.100^{* * *}$ & 0.021 & 0.045 & 0.034 & $0.077^{* * *}$ & 0.019 & -0.042 & 0.026 \\
\hline-0.003 & 0.031 & -0.020 & 0.036 & -0.002 & 0.031 & -0.030 & 0.057 & -0.010 & 0.030 & 0.007 & 0.039 \\
\hline 0.028 & 0.029 & 0.024 & 0.044 & 0.033 & 0.029 & 0.047 & 0.040 & 0.020 & 0.027 & $-0.186^{* * *}$ & 0.039 \\
\hline $0.070^{* *}$ & 0.033 & $0.187^{* * *}$ & 0.039 & $0.071^{* *}$ & 0.033 & -0.027 & 0.042 & $0.057^{*}$ & 0.031 & -0.033 & 0.044 \\
\hline$-0.080^{* * *}$ & 0.027 & -0.012 & 0.030 & $-0.093^{* * *}$ & 0.026 & $-0.065 *$ & 0.039 & $-0.065^{* *}$ & 0.025 & 0.025 & 0.032 \\
\hline$-0.068^{* * *}$ & 0.023 & $-0.067^{* * *}$ & 0.023 & $-0.066 * * *$ & 0.023 & $-0.134^{* * *}$ & 0.037 & $-0.081^{* * *}$ & 0.021 & -0.017 & 0.035 \\
\hline-0.006 & 0.020 & 0.003 & 0.019 & -0.005 & 0.019 & 0.000 & 0.043 & -0.011 & 0.019 & 0.039 & 0.028 \\
\hline-0.003 & 0.022 & -0.013 & 0.021 & -0.004 & 0.022 & -0.023 & 0.042 & 0.000 & 0.021 & 0.030 & 0.033 \\
\hline-0.034 & 0.039 & -0.004 & 0.036 & -0.032 & 0.038 & -0.082 & 0.061 & -0.036 & 0.038 & 0.004 & 0.048 \\
\hline$-0.228^{* * *}$ & 0.028 & $-0.185^{* * *}$ & 0.028 & $-0.225^{* * *}$ & 0.028 & $-0.350 * * *$ & 0.045 & $-0.148^{* * *}$ & 0.028 & $0.227^{* * *}$ & 0.038 \\
\hline$-0.025^{* *}$ & 0.012 & -0.011 & 0.012 & $-0.025^{* *}$ & 0.012 & -0.002 & 0.029 & $-0.027^{* *}$ & 0.013 & -0.023 & 0.019 \\
\hline 0.022 & 0.043 & 0.015 & 0.049 & 0.023 & 0.043 & 0.030 & 0.064 & -0.010 & 0.042 & $-0.250^{* * *}$ & 0.060 \\
\hline-0.053 & 0.038 & $-0.056^{*}$ & 0.032 & -0.054 & 0.038 & -0.070 & 0.075 & -0.055 & 0.037 & 0.052 & 0.043 \\
\hline-0.039 & 0.035 & $-0.067^{* *}$ & 0.031 & -0.038 & 0.035 & -0.066 & 0.062 & -0.050 & 0.034 & -0.038 & 0.043 \\
\hline $0.076^{* *}$ & 0.034 & $0.084^{* *}$ & 0.041 & $0.075^{* *}$ & 0.034 & $0.132^{* *}$ & 0.063 & $0.093^{* * *}$ & 0.033 & $-0.145^{* * *}$ & 0.056 \\
\hline $0.117^{* * *}$ & 0.039 & 0.020 & 0.044 & $0.115^{* * *}$ & 0.039 & $0.175^{* * *}$ & 0.063 & $0.109^{* * *}$ & 0.038 & $0.201^{* * *}$ & 0.059 \\
\hline $0.169^{* * *}$ & 0.026 & $0.090^{* * *}$ & 0.027 & $0.167^{* * *}$ & 0.026 & $0.216^{* * *}$ & 0.035 & $0.142^{* * *}$ & 0.024 & 0.032 & 0.036 \\
\hline-0.041 & 0.031 & 0.000 & 0.036 & -0.042 & 0.031 & -0.010 & 0.032 & -0.040 & 0.030 & 0.041 & 0.043 \\
\hline$-0.458 * * *$ & 0.064 & $-0.424^{* * *}$ & 0.061 & $-0.455^{* * *}$ & 0.064 & $-0.465 * * *$ & 0.084 & $-0.421 * * *$ & 0.066 & $0.328 * * *$ & 0.088 \\
\hline-0.038 & 0.030 & -0.035 & 0.036 & -0.035 & 0.030 & -0.033 & 0.040 & $-0.064^{* *}$ & 0.029 & 0.025 & 0.045 \\
\hline-0.034 & 0.037 & 0.002 & 0.036 & -0.036 & 0.037 & -0.053 & 0.065 & -0.040 & 0.037 & $0.116^{*}$ & 0.061 \\
\hline no & & yes & & no & & & & no & & & \\
\hline
\end{tabular}

Segregation

Fraction of Black Residents

Racial Segregation Theil Index

Share with Com

Income Distribution

Household Income per Capita for Working-Age Adults

Gini Bottom 99\%

Top $1 \%$ Income Share for Parent

Tax

Local Tax Rate

Local Government Expenditures per Capita

State EITC Exposure

State Income Tax Progressivity

K-12 Education

School Expenditure per Student

Teacher-Student Ratio

High School Dror

\section{College}

Number of Colleges per Capita

Mean College Tuition

College Graduation Rate

\section{Local Labor Market}

Labor Force Participation Rate

Fraction Working in Manufacturing

Teenage Labor Force Participation Rat

Migration

Migration Inflow Rate

Migration Outflow Rate

Fraction of Foreign Born Residents

\section{Social Capital}

Social Capital Index

Fraction Religous

Violent Crime Rate

\section{Family Structure}

Fraction of Children with Single Mothers

Fraction of Adults Divorced

Fraction of Adults Married

State Fixed Effects

Controls 
Table 8: BMA Regressions - Posterior Model Probabilities (sample without College)

This table uses a larger sample size (633 commuting zones) than our baseline results at the expense of excluding the College variables from the sample space. Each cell reports the posterior inclusion probability (PIP), which is the sum of posterior model probabilities over all those models that contain that variable, using the Benchmark Priors (g-BRIC).

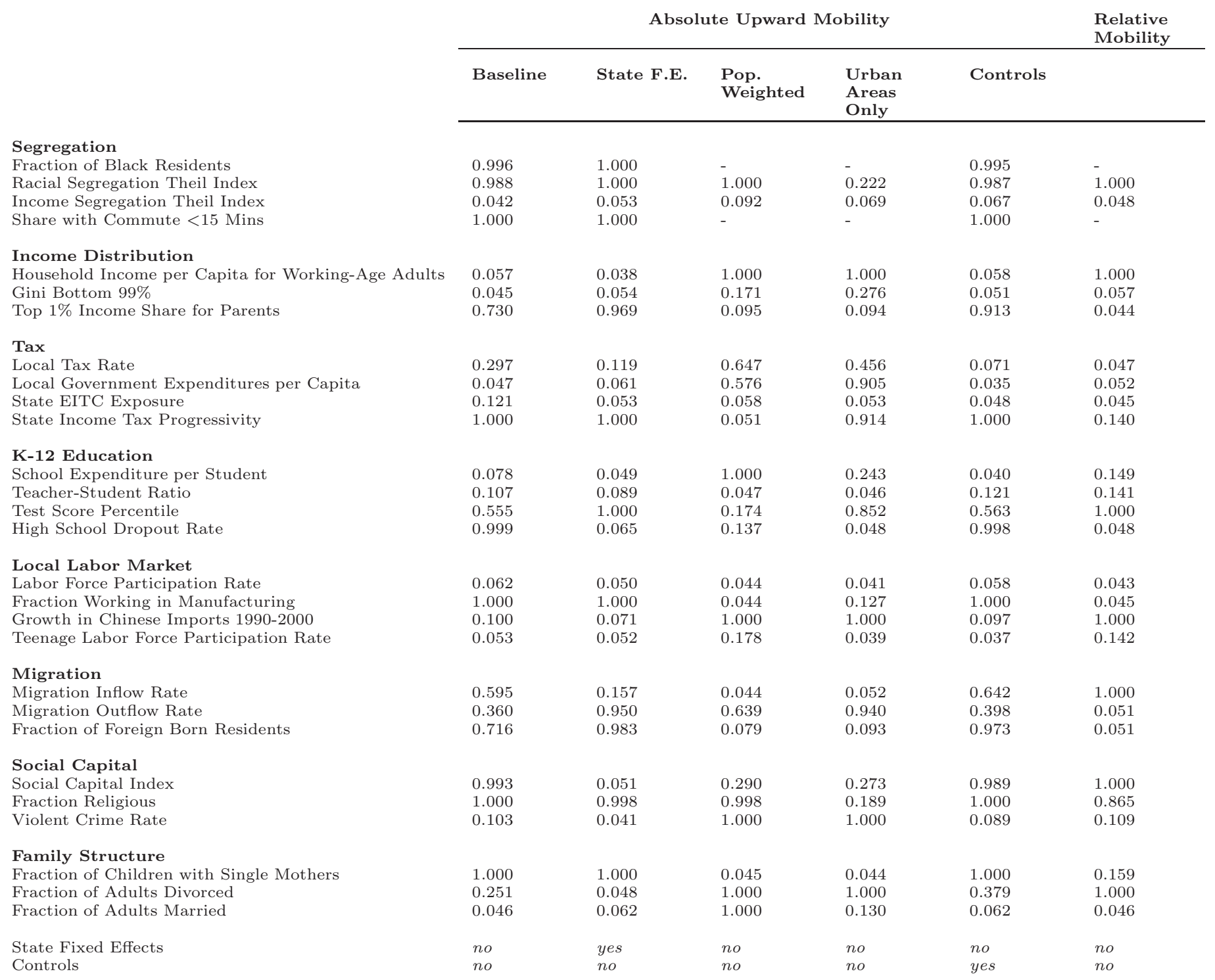


Table 9: BMA Regressions - Posterior Means and Standard Errors (sample without College)

This table uses a larger sample size (633 commuting zones) than our baseline results at the expense of excluding the College variables from the sample space. It reports the posterior mean (PM) and the posterior standard error (PSE) for BMA regressions of a measure of mobility on the model space spanned by the various subsets of determinants and using the Benchmark Priors (g-BRIC). The PM is the average of the LS coefficient estimates (COEF) of individual models weighted by the posterior model probability and the PSE is the BMA estimate for the standard error (SE).***, **, and * denote significance of the regression coefficient at $1 \%, 5 \%$, and $10 \%$, respectively.

Absolute Upward Mobility

Relative Mobility

Segregation

Raction of Black Res

Racial Segregation Theil Index

Income Segregation Theil Index

Share with Comite $<15$ Mins

Income Distribution

Household Income per Capita for Working-Age Adults

Top 1\% Income Share for Parent

Tax

Local Tax Rate

Local Government Expenditures per Capita

State Income Tax Progressivity

\section{K-12 Education}

School Expenditure per Student

Teacher-Student Ratio

High School Dropout Rate

\section{Local Labor Market}

Labor Force Participation Rate

Fraction Working in Manufacturing

Growth in Chinese Imports 1990-2000

Teenage Labor Force Participation Rate

Migration

Migration Inflow Rate

Fraction of Foreign Born Residents

Social Capital

Social Capital Index

Fraction Religious

Violent Crime Rate

Family Structure

Fraction of Children with Single Mothers

Fraction of Adults Divorced

Fraction of Adults Married

State Fixed Effects

Control

\begin{tabular}{|c|c|c|c|c|c|c|c|c|c|c|c|}
\hline \multicolumn{2}{|c|}{ Baseline } & \multicolumn{2}{|c|}{ State F.E. } & \multicolumn{2}{|c|}{ Pop. Weighted } & \multicolumn{2}{|c|}{ Urban Areas Only } & \multicolumn{2}{|c|}{ Controls } & \multirow[b]{2}{*}{ COEF } & \multirow[b]{2}{*}{ SE } \\
\hline COEF & $\mathrm{SE}$ & COEF & $\mathrm{SE}$ & $\mathrm{COEF}$ & $\mathrm{SE}$ & COEF & SE & COEF & SE & & \\
\hline $0.175^{* * *}$ & 0.040 & -0.001 & 0.005 & - & - & - & - & $0.183^{* * *}$ & 0.040 & - & - \\
\hline$-0.075^{* * *}$ & 0.021 & 0.270 & 0.027 & $-0.107^{* * *}$ & 0.020 & -0.016 & 0.035 & $-0.074 * * *$ & 0.021 & $0.155^{* * *}$ & 0.017 \\
\hline 0.000 & 0.007 & 0.000 & 0.006 & 0.004 & 0.015 & -0.003 & 0.018 & 0.002 & 0.011 & -0.001 & 0.018 \\
\hline $0.256^{* * *}$ & 0.032 & -0.001 & 0.007 & - & - & - & - & $0.242^{* * *}$ & 0.032 & - & - \\
\hline 0.001 & 0.011 & $0.098^{* * *}$ & 0.026 & $0.194^{* * *}$ & 0.036 & $0.267^{* * *}$ & 0.045 & 0.002 & 0.014 & $-0.094 * * *$ & 0.019 \\
\hline-0.001 & 0.006 & $0.286^{* * *}$ & 0.032 & -0.011 & 0.029 & -0.035 & 0.066 & -0.001 & 0.006 & 0.002 & 0.016 \\
\hline-0.071 & 0.052 & $-0.173^{* * *}$ & 0.021 & -0.004 & 0.016 & -0.007 & 0.030 & $-0.094^{* *}$ & 0.041 & 0.000 & 0.007 \\
\hline 0.018 & 0.031 & $0.093^{* * *}$ & 0.022 & 0.074 & 0.064 & 0.063 & 0.080 & 0.002 & 0.011 & -0.001 & 0.010 \\
\hline 0.001 & 0.008 & -0.001 & 0.005 & 0.037 & 0.037 & $0.097^{* *}$ & 0.043 & 0.000 & 0.005 & -0.008 & 0.068 \\
\hline 0.004 & 0.011 & 0.001 & 0.009 & 0.001 & 0.010 & -0.001 & 0.010 & 0.001 & 0.005 & 0.000 & 0.000 \\
\hline $0.103^{* * *}$ & 0.018 & 0.000 & 0.005 & 0.001 & 0.005 & $0.100^{* * *}$ & 0.043 & $0.080^{* * *}$ & 0.017 & 0.000 & 0.000 \\
\hline 0.002 & 0.011 & -0.001 & 0.008 & $0.091^{* * *}$ & 0.019 & 0.017 & 0.035 & 0.000 & 0.005 & 0.000 & 0.001 \\
\hline 0.004 & 0.014 & -0.001 & 0.007 & 0.000 & 0.006 & 0.000 & 0.011 & 0.005 & 0.015 & 0.000 & 0.001 \\
\hline 0.042 & 0.043 & -0.001 & 0.005 & 0.008 & 0.019 & $0.107^{*}$ & 0.056 & 0.039 & 0.040 & -0.005 & 0.001 \\
\hline$-0.101^{* * *}$ & 0.022 & 0.001 & 0.009 & 0.007 & 0.020 & 0.001 & 0.011 & $-0.091 * * *$ & 0.021 & 0.000 & 0.000 \\
\hline-0.002 & 0.010 & -0.010 & 0.028 & 0.000 & 0.005 & 0.000 & 0.007 & -0.001 & 0.009 & 0.000 & 0.002 \\
\hline$-0.222^{* * *}$ & 0.025 & $-0.100 * * *$ & 0.031 & 0.000 & 0.006 & -0.009 & 0.028 & $-0.156^{* * *}$ & 0.025 & 0.000 & 0.008 \\
\hline-0.003 & 0.010 & $-0.082 * * *$ & 0.017 & $-0.204^{* * *}$ & 0.025 & $-0.339 * * *$ & 0.037 & -0.003 & 0.009 & $0.227^{* * *}$ & 0.023 \\
\hline 0.002 & 0.011 & 0.000 & 0.006 & -0.006 & 0.015 & 0.000 & 0.006 & 0.000 & 0.007 & 0.000 & 0.001 \\
\hline-0.042 & 0.040 & 0.001 & 0.008 & 0.000 & 0.008 & -0.001 & 0.013 & -0.052 & 0.043 & $-12.337 * * *$ & 2.307 \\
\hline-0.024 & 0.036 & $-0.481^{* * *}$ & 0.039 & -0.041 & 0.036 & $-0.180^{* * *}$ & 0.062 & -0.029 & 0.039 & 0.004 & 0.054 \\
\hline 0.057 & 0.042 & 0.001 & 0.005 & -0.001 & 0.011 & -0.008 & 0.033 & $0.097^{* * *}$ & 0.030 & -0.006 & 0.065 \\
\hline $0.141^{* * *}$ & 0.038 & $0.171^{* * *}$ & 0.021 & 0.016 & 0.029 & 0.032 & 0.062 & $0.132^{* * *}$ & 0.036 & $-0.252^{* * *}$ & 0.039 \\
\hline $0.163^{* * *}$ & 0.022 & 0.005 & 0.015 & $0.152^{* * *}$ & 0.035 & 0.019 & 0.049 & $0.140^{* * *}$ & 0.021 & $0.006^{* *}$ & 0.003 \\
\hline-0.005 & 0.017 & 0.003 & 0.014 & $0.164^{* * *}$ & 0.023 & $0.215^{* * *}$ & 0.033 & -0.004 & 0.015 & 0.002 & 0.007 \\
\hline$-0.485^{* * *}$ & 0.047 & 0.000 & 0.008 & -0.001 & 0.007 & 0.001 & 0.008 & $-0.453^{* * *}$ & 0.045 & 0.493 & 1.360 \\
\hline-0.014 & 0.029 & $0.198^{* * *}$ & 0.028 & $-0.360^{* * *}$ & 0.039 & $-0.564^{* * *}$ & 0.062 & -0.023 & 0.034 & $0.447^{* * *}$ & 0.043 \\
\hline-0.001 & 0.008 & $-0.111^{* * *}$ & 0.036 & $-0.133^{* * *}$ & 0.022 & -0.007 & 0.022 & -0.002 & 0.011 & -0.002 & 0.025 \\
\hline no & & yes & & no & & & & no & & no & \\
\hline no & & no & & no & & & & yes & & no & \\
\hline
\end{tabular}


Table 10: Robustness to Priors Specification - Posterior Inclusion Probabilities

This table reports posterior inclusion probability (PIP) for various specifications of priors for the baseline model space of Table 6 . The first six columns provide variations of fixed prior structures while the last four use a flexible prior structure based on a hyper-g prior, whose data-dependent shrinkage adapts posterior model distributions to data quality

Fixed Priors

Model Priors

Parameter Priors

Segregatio

Fraction of Black Residents

Racial Segregation Theil Index

Share with Commute $<15$ Min

Household Income

Top $1 \%$ Income Share for Parent

Local Tax Rate

Local Government Expenditures per Capit

\begin{tabular}{|c|c|c|c|c|c|c|c|c|c|}
\hline \multicolumn{6}{|c|}{ Fixed Priors } & \multicolumn{4}{|c|}{ Flexible Priors } \\
\hline \multicolumn{2}{|c|}{ Uniform } & \multicolumn{2}{|c|}{ Hierarchical } & \multicolumn{2}{|c|}{ Tesselation } & \multicolumn{2}{|c|}{ Uniform } & \multicolumn{2}{|c|}{ Hierarchical } \\
\hline g-BRIC & g-UIP & g-BRIC & g-UIP & g-BRIC & g-UIP & hg-BRIC & hg-UIP & hg-BRIC & hg-UIP \\
\hline 0.985 & 0.990 & 0.963 & 0.956 & 0.986 & 0.989 & 0.991 & 0.992 & 0.945 & 0.947 \\
\hline 0.989 & 0.992 & 0.261 & 0.339 & 0.989 & 0.990 & 0.992 & 0.992 & 0.395 & 0.393 \\
\hline 0.038 & 0.051 & 0.001 & 0.002 & 0.038 & 0.050 & 0.085 & 0.085 & 0.002 & 0.003 \\
\hline 1.000 & 1.000 & 1.000 & 1.000 & 1.000 & 1.000 & 1.000 & 1.000 & 1.000 & 1.000 \\
\hline 0.061 & 0.075 & 0.003 & 0.004 & 0.060 & 0.073 & 0.109 & 0.109 & 0.005 & 0.005 \\
\hline 0.037 & 0.050 & 0.001 & 0.001 & 0.037 & 0.051 & 0.083 & 0.083 & 0.002 & 0.002 \\
\hline 0.841 & 0.879 & 0.015 & 0.021 & 0.842 & 0.883 & 0.904 & 0.901 & 0.029 & 0.030 \\
\hline 0.250 & 0.258 & 0.094 & 0.122 & 0.251 & 0.253 & 0.272 & 0.276 & 0.151 & 0.150 \\
\hline 0.043 & 0.055 & 0.003 & 0.003 & 0.043 & 0.055 & 0.084 & 0.082 & 0.004 & 0.004 \\
\hline 0.098 & 0.121 & 0.008 & 0.009 & 0.095 & 0.116 & 0.166 & 0.167 & 0.010 & 0.010 \\
\hline 1.000 & 1.000 & 1.000 & 1.000 & 1.000 & 1.000 & 1.000 & 1.000 & 1.000 & 1.000 \\
\hline 0.072 & 0.083 & 0.018 & 0.025 & 0.072 & 0.083 & 0.114 & 0.113 & 0.028 & 0.029 \\
\hline 0.058 & 0.075 & 0.001 & 0.002 & 0.058 & 0.077 & 0.117 & 0.119 & 0.002 & 0.002 \\
\hline 0.398 & 0.463 & 0.007 & 0.010 & 0.392 & 0.466 & 0.558 & 0.561 & 0.011 & 0.010 \\
\hline 0.992 & 0.994 & 0.991 & 0.989 & 0.992 & 0.993 & 0.994 & 0.994 & 0.988 & 0.988 \\
\hline 0.831 & 0.869 & 0.048 & 0.068 & 0.832 & 0.870 & 0.896 & 0.894 & 0.089 & 0.090 \\
\hline 0.033 & 0.042 & 0.001 & 0.002 & 0.032 & 0.043 & 0.074 & 0.076 & 0.002 & 0.002 \\
\hline 0.037 & 0.049 & 0.002 & 0.002 & 0.037 & 0.050 & 0.081 & 0.082 & 0.003 & 0.003 \\
\hline 0.059 & 0.080 & 0.001 & 0.002 & 0.056 & 0.081 & 0.134 & 0.132 & 0.003 & 0.002 \\
\hline 1.000 & 1.000 & 1.000 & 1.000 & 1.000 & 1.000 & 1.000 & 1.000 & 1.000 & 1.000 \\
\hline 0.101 & 0.127 & 0.004 & 0.005 & 0.096 & 0.127 & 0.188 & 0.192 & 0.006 & 0.007 \\
\hline 0.044 & 0.058 & 0.001 & 0.002 & 0.046 & 0.058 & 0.091 & 0.089 & 0.002 & 0.003 \\
\hline 0.699 & 0.709 & 0.049 & 0.069 & 0.703 & 0.698 & 0.686 & 0.686 & 0.084 & 0.087 \\
\hline 0.302 & 0.324 & 0.010 & 0.014 & 0.297 & 0.334 & 0.388 & 0.388 & 0.018 & 0.018 \\
\hline 0.609 & 0.663 & 0.022 & 0.031 & 0.605 & 0.666 & 0.731 & 0.732 & 0.038 & 0.040 \\
\hline 0.995 & 0.995 & 0.999 & 1.000 & 0.994 & 0.995 & 0.994 & 0.995 & 0.999 & 0.999 \\
\hline 1.000 & 1.000 & 1.000 & 1.000 & 1.000 & 1.000 & 1.000 & 1.000 & 1.000 & 1.000 \\
\hline 0.095 & 0.125 & 0.003 & 0.004 & 0.096 & 0.126 & 0.189 & 0.194 & 0.005 & 0.005 \\
\hline 1.000 & 1.000 & 1.000 & 1.000 & 1.000 & 1.000 & 1.000 & 1.000 & 1.000 & 1.000 \\
\hline 0.453 & 0.477 & 0.073 & 0.096 & 0.459 & 0.474 & 0.504 & 0.495 & 0.121 & 0.117 \\
\hline 0.051 & 0.068 & 0.002 & 0.003 & 0.051 & 0.073 & 0.112 & 0.114 & 0.004 & 0.004 \\
\hline
\end{tabular}

\section{K-12 Educatio}

School Expenditure per Student

Teacher-Student Ratio

High School Dropout Rate

College

Number of Colleges per Capita

Mean College Tuition

\section{Local Labor Market}

Labor Force Participation Rate

Fraction Working in Manufacturing

Teerth in Chiser Force Participation

\section{Migration}

Migration Inflow Rate

Migration Outflow Rate

Fraction of Foreign Born Residents

Social Capital

Social Capital Index

Fraction Religious

Violent Crime Rate

Family Structure

Fraction of Children with Single Mother

Fraction of Adults Divorced

$0.051-0.068$

0.002

0.003 


\section{Table 11: Robustness to Priors Specification - Posterior Means and Standard Errors}

This table reports the posterior mean (PM) and the posterior standard error (PSE) for various specifications of priors for the baseline model space of Table 6. Panel provide variations of fixed prior structures while Panel B reports results using a flexible prior structure based on a hyper-g prior, whose data-dependent shrinkage adapts posterior model
distributions to data quality. ${ }^{* *},{ }^{* *}$, and ${ }^{*}$ denote significance of the regression coefficient at $1 \%, 5 \%$, and $10 \%$, respectively.

Model Priors

Parameter Priors

Segregation

Fraction of Black Residents

Racial Segregation Theil Index

Sheoregren Theil Index

Income Distribution

Householl Income per Capita for Working-Age Adults Gini Bottom 99\%

Top $1 \%$ Income Share for Parent

Tax

Local Tax Rate

Local Government Expenditures per Capita

State EITC Exposure

State Income Tax Progressivity

K-12 Education

School Expenditure per Student

Teacher-Student Ratio

High School Drop

College

Number of Colleges per Capita

Mean College Tuition

College Graduation Rate

Local Labor Market

Labor Force Participation Rate

Fraction Working in Manufacturing

Growth in Chinese Imports 1990-2000

Teenage Labor Force Participation Rate

Migration

Migration Inflow Rate

Migration Outflow Rate

Fraction of Foreign Born Residents

\section{Social Capital}

Social Capital Index

Fraction Religous

Violent Crime Rate

Family Structure

Fraction of Children with Single Mothers

Fraction of Adults Divorced

Fraction of Adults Marrie

Table continued on next page...
Panel A: Fixed Priors

\begin{tabular}{|c|c|c|c|c|c|c|c|c|c|c|c|}
\hline \multicolumn{4}{|c|}{ Uniform } & \multicolumn{4}{|c|}{ Hierarchical } & \multicolumn{4}{|c|}{ Tesselation } \\
\hline \multicolumn{2}{|c|}{ g-BRIC } & \multicolumn{2}{|c|}{ g-UIP } & \multicolumn{2}{|c|}{ g-BRIC } & \multicolumn{2}{|c|}{ g-UIP } & \multicolumn{2}{|c|}{ g-BRIC } & \multicolumn{2}{|c|}{ g-UIP } \\
\hline COEF & SE & COEF & SE & COEF & SE & COEF & SE & COEF & $\mathrm{SE}$ & COEF & SE \\
\hline $0.158^{* * *}$ & 0.046 & $0.159^{* * *}$ & 0.045 & $0.169 * * *$ & 0.045 & $0.166^{* * *}$ & 0.047 & $0.158^{* * *}$ & 0.046 & $0.159^{* * *}$ & 0.045 \\
\hline$-0.078^{* * *}$ & 0.021 & $-0.078^{* * *}$ & 0.021 & -0.018 & 0.033 & -0.024 & 0.035 & $-0.078^{* * *}$ & 0.021 & $-0.078^{* * *}$ & 0.021 \\
\hline 0.000 & 0.006 & 0.000 & 0.007 & 0.000 & 0.001 & 0.000 & 0.001 & 0.000 & 0.007 & 0.000 & 0.007 \\
\hline $0.270^{* * *}$ & 0.034 & $0.270^{* * *}$ & 0.034 & $0.297 * * *$ & 0.033 & $0.294^{* * *}$ & 0.034 & $0.270 * * *$ & 0.034 & $0.271^{* * *}$ & 0.034 \\
\hline 0.001 & 0.012 & 0.001 & 0.012 & 0.000 & 0.003 & 0.000 & 0.003 & 0.001 & 0.012 & 0.001 & 0.012 \\
\hline 0.000 & 0.005 & -0.001 & 0.006 & 0.000 & 0.001 & 0.000 & 0.001 & 0.000 & 0.005 & -0.001 & 0.006 \\
\hline-0.087 & 0.048 & $-0.091 * *$ & 0.046 & -0.001 & 0.009 & -0.002 & 0.012 & $-0.087^{*}$ & 0.048 & $-0.092^{* *}$ & 0.045 \\
\hline 0.014 & 0.027 & 0.013 & 0.026 & 0.007 & 0.022 & 0.009 & 0.024 & 0.014 & 0.027 & 0.013 & 0.026 \\
\hline 0.001 & 0.007 & 0.001 & 0.008 & 0.000 & 0.002 & 0.000 & 0.003 & 0.001 & 0.007 & 0.001 & 0.008 \\
\hline 0.003 & 0.010 & 0.003 & 0.011 & 0.000 & 0.003 & 0.000 & 0.004 & 0.003 & 0.010 & 0.003 & 0.010 \\
\hline $0.101^{* * *}$ & 0.017 & $0.101^{* * *}$ & 0.017 & $0.107^{* * *}$ & 0.016 & $0.107^{* * *}$ & 0.017 & $0.101^{* * *}$ & 0.017 & $0.101^{* * *}$ & 0.017 \\
\hline 0.002 & 0.010 & 0.002 & 0.010 & 0.001 & 0.007 & 0.001 & 0.008 & 0.002 & 0.010 & 0.002 & 0.010 \\
\hline 0.001 & 0.009 & 0.002 & 0.010 & 0.000 & 0.001 & 0.000 & 0.001 & 0.002 & 0.009 & 0.002 & 0.010 \\
\hline 0.028 & 0.039 & 0.032 & 0.040 & 0.000 & 0.005 & 0.001 & 0.006 & 0.028 & 0.039 & 0.033 & 0.040 \\
\hline$-0.090^{* * *}$ & 0.024 & $-0.089^{* * *}$ & 0.023 & $-0.112^{* * *}$ & 0.025 & $-0.110^{* * *}$ & 0.025 & $-0.090^{* * *}$ & 0.024 & $-0.089 * * *$ & 0.023 \\
\hline-0.058 & 0.033 & $-0.061^{* *}$ & 0.031 & -0.003 & 0.015 & -0.004 & 0.017 & $-0.058^{*}$ & 0.033 & $-0.061^{* *}$ & 0.031 \\
\hline 0.000 & 0.003 & 0.000 & 0.004 & 0.000 & 0.001 & 0.000 & 0.001 & 0.000 & 0.003 & 0.000 & 0.004 \\
\hline 0.000 & 0.004 & 0.000 & 0.005 & 0.000 & 0.001 & 0.000 & 0.001 & 0.000 & 0.004 & 0.000 & 0.005 \\
\hline-0.002 & 0.010 & -0.002 & 0.011 & 0.000 & 0.001 & 0.000 & 0.002 & -0.001 & 0.009 & -0.002 & 0.011 \\
\hline$-0.236^{* * *}$ & 0.025 & $-0.236^{* * *}$ & 0.025 & $-0.200^{* * *}$ & 0.021 & $-0.200^{* * *}$ & 0.021 & $-0.236 * * *$ & 0.025 & $-0.236^{* * *}$ & 0.025 \\
\hline-0.003 & 0.010 & -0.003 & 0.011 & 0.000 & 0.002 & 0.000 & 0.003 & -0.003 & 0.010 & -0.004 & 0.011 \\
\hline 0.001 & 0.010 & 0.001 & 0.011 & 0.000 & 0.002 & 0.000 & 0.002 & 0.001 & 0.010 & 0.001 & 0.011 \\
\hline-0.055 & 0.041 & -0.056 & 0.042 & -0.003 & 0.013 & -0.004 & 0.016 & -0.056 & 0.041 & -0.056 & 0.042 \\
\hline-0.021 & 0.036 & -0.022 & 0.036 & 0.000 & 0.004 & -0.001 & 0.005 & -0.021 & 0.036 & -0.023 & 0.037 \\
\hline 0.044 & 0.041 & 0.048 & 0.041 & 0.001 & 0.008 & 0.002 & 0.010 & 0.044 & 0.041 & 0.048 & 0.041 \\
\hline $0.141^{* * *}$ & 0.036 & $0.139 * * *$ & 0.035 & $0.178^{* * *}$ & 0.026 & $0.178^{* * *}$ & 0.026 & $0.141^{* * *}$ & 0.036 & $0.138^{* * *}$ & 0.035 \\
\hline $0.164^{* * *}$ & 0.022 & $0.164^{* * *}$ & 0.022 & $0.158^{* * *}$ & 0.022 & $0.159^{* * *}$ & 0.022 & $0.164^{* * *}$ & 0.022 & $0.164^{* * *}$ & 0.022 \\
\hline-0.004 & 0.016 & -0.006 & 0.019 & 0.000 & 0.003 & 0.000 & 0.003 & -0.004 & 0.016 & -0.006 & 0.019 \\
\hline$-0.467^{* * *}$ & 0.049 & $-0.462 * * *$ & 0.048 & $-0.550 * * *$ & 0.049 & $-0.545 * * *$ & 0.052 & $-0.467 * * *$ & 0.049 & $-0.462^{* * *}$ & 0.048 \\
\hline-0.032 & 0.039 & -0.032 & 0.039 & -0.007 & 0.027 & -0.009 & 0.030 & -0.032 & 0.040 & -0.032 & 0.039 \\
\hline-0.001 & 0.010 & -0.002 & 0.011 & 0.000 & 0.002 & 0.000 & 0.002 & -0.001 & 0.010 & -0.002 & 0.012 \\
\hline
\end{tabular}




\section{Table 11 continued}

Model Priors

Parameter Priors

Segregation

Fraction of Black Resident

Racial Segregation Theil Index

Income Segregation Theil Index

Share with Commute $<15$ Min

Income Distribution

Household Income per Capita for Working-Age Adults Gini Bottom 99\%

Top $1 \%$ Income Share for Parents

Tax

Local Tax Rate

Local Government Expenditures per Capita

State EITC Exposure

State Income Tax Progressivity

\section{K-12 Education}

School Expenditure per Student

Teacher-Student Ratio

Test Score Percentile
High School Dropout Rate

\section{College}

Number of Colleges per Capita

Mean College Tuition

College Graduation Rate

\section{Local Labor Market}

Labor Force Participation Rate

Fraction Working in Manufacturing

Tewa

\section{Migration}

Migration Inflow Rate

Migration Out Rate

Fraction of Foreign Born Residents

\section{Social Capital}

Social Capital Index

Social Capital Index

Violent Crime Rate

Family Structure

Fraction of Children with Single Mothers

Fraction of Adults Divorced

Fraction of Adults Married
Panel B: Flexible Priors

\begin{tabular}{|c|c|c|c|c|c|c|c|}
\hline \multicolumn{4}{|c|}{ Uniform } & \multicolumn{4}{|c|}{ Hierarchical } \\
\hline \multicolumn{2}{|c|}{ g-BRIC } & \multicolumn{2}{|c|}{ g-UIP } & \multicolumn{2}{|c|}{ g-BRIC } & \multicolumn{2}{|c|}{ g-UIP } \\
\hline COEF & $\mathrm{SE}$ & COEF & $\mathrm{SE}$ & COEF & $\mathrm{SE}$ & COEF & $\mathrm{SE}$ \\
\hline $0.160^{* * *}$ & 0.045 & $0.161^{* * *}$ & 0.045 & $0.163 * * *$ & 0.050 & $0.163^{* * *}$ & 0.050 \\
\hline$-0.078 * * *$ & 0.021 & $-0.078^{* * *}$ & 0.021 & -0.028 & 0.037 & -0.028 & 0.037 \\
\hline-0.001 & 0.010 & -0.001 & 0.010 & 0.000 & 0.001 & 0.000 & 0.002 \\
\hline $0.270^{* * *}$ & 0.034 & $0.270^{* * *}$ & 0.034 & $0.291 * * *$ & 0.035 & $0.291^{* * *}$ & 0.035 \\
\hline 0.000 & 0.014 & 0.000 & 0.014 & 0.000 & 0.004 & 0.000 & 0.004 \\
\hline-0.001 & 0.007 & -0.001 & 0.007 & 0.000 & 0.001 & 0.000 & 0.001 \\
\hline$-0.095 * *$ & 0.044 & $-0.094^{* *}$ & 0.044 & -0.002 & 0.014 & -0.002 & 0.015 \\
\hline 0.013 & 0.025 & 0.013 & 0.025 & 0.011 & 0.027 & 0.011 & 0.027 \\
\hline 0.001 & 0.010 & 0.001 & 0.010 & 0.000 & 0.003 & 0.000 & 0.003 \\
\hline 0.004 & 0.012 & 0.004 & 0.012 & 0.000 & 0.004 & 0.000 & 0.004 \\
\hline $0.101^{* * *}$ & 0.018 & $0.101^{* * *}$ & 0.018 & $0.107^{* * *}$ & 0.017 & $0.107 * * *$ & 0.017 \\
\hline 0.002 & 0.011 & 0.002 & 0.011 & 0.001 & 0.009 & 0.001 & 0.009 \\
\hline 0.003 & 0.012 & 0.003 & 0.012 & 0.000 & 0.002 & 0.000 & 0.001 \\
\hline 0.039 & 0.040 & 0.039 & 0.040 & 0.001 & 0.007 & 0.001 & 0.006 \\
\hline$-0.088^{* * *}$ & 0.023 & $-0.088^{* * *}$ & 0.023 & $-0.109^{* * *}$ & 0.026 & $-0.109 * * *$ & 0.026 \\
\hline$-0.062^{* *}$ & 0.030 & $-0.062^{* *}$ & 0.030 & -0.006 & 0.020 & -0.006 & 0.020 \\
\hline 0.000 & 0.005 & 0.000 & 0.005 & 0.000 & 0.001 & 0.000 & 0.001 \\
\hline 0.000 & 0.006 & 0.000 & 0.006 & 0.000 & 0.001 & 0.000 & 0.001 \\
\hline-0.004 & 0.015 & -0.004 & 0.015 & 0.000 & 0.002 & 0.000 & 0.002 \\
\hline$-0.236^{* * *}$ & 0.025 & $-0.235^{* * *}$ & 0.025 & $-0.201 * * *$ & 0.022 & $-0.201 * * *$ & 0.022 \\
\hline-0.005 & 0.013 & -0.005 & 0.013 & 0.000 & 0.003 & 0.000 & 0.003 \\
\hline 0.002 & 0.013 & 0.002 & 0.013 & 0.000 & 0.002 & 0.000 & 0.003 \\
\hline-0.054 & 0.042 & -0.054 & 0.042 & -0.005 & 0.018 & -0.005 & 0.018 \\
\hline-0.026 & 0.038 & -0.026 & 0.038 & -0.001 & 0.006 & -0.001 & 0.006 \\
\hline 0.053 & 0.040 & 0.054 & 0.040 & 0.002 & 0.011 & 0.002 & 0.011 \\
\hline $0.136 * * *$ & 0.036 & $0.136^{* * *}$ & 0.036 & $0.178^{* * *}$ & 0.027 & $0.178^{* * *}$ & 0.027 \\
\hline $0.164^{* * *}$ & 0.022 & $0.164 * * *$ & 0.022 & $0.159 * * *$ & 0.022 & $0.159^{* * *}$ & 0.022 \\
\hline-0.009 & 0.022 & -0.009 & 0.022 & 0.000 & 0.004 & 0.000 & 0.004 \\
\hline$-0.456^{* * *}$ & 0.049 & $-0.456^{* * *}$ & 0.049 & $-0.539^{* * *}$ & 0.055 & $-0.540 * * *$ & 0.055 \\
\hline-0.032 & 0.038 & -0.031 & 0.037 & -0.011 & 0.033 & -0.011 & 0.033 \\
\hline-0.003 & 0.015 & -0.003 & 0.015 & 0.000 & 0.002 & 0.000 & 0.003 \\
\hline
\end{tabular}


Table 12: BMA Results for Quintiles of Commuting Zones by Average Parental Income

A according to income.

\begin{tabular}{|c|c|c|c|c|c|c|c|c|c|c|c|c|c|c|c|}
\hline & \multicolumn{3}{|c|}{ 1st QUINTILE } & \multicolumn{3}{|c|}{ 2nd QUINTILE } & \multicolumn{3}{|c|}{ 3rd QUINTILE } & \multicolumn{3}{|c|}{ 4th QUINTILE } & \multicolumn{3}{|c|}{ 5th QUINTILE } \\
\hline & PIP & $\mathbf{P M}$ & PSE & PIP & PM & PSE & PIP & $\mathbf{P M}$ & PSE & PIP & $\mathbf{P M}$ & PSE & PIP & PM & PSE \\
\hline \multicolumn{16}{|l|}{ Segregation } \\
\hline Fraction of Black Residents & 0.437 & 0.069 & 0.088 & 0.642 & 0.146 & 0.124 & 0.044 & 0.002 & 0.021 & 0.040 & 0.002 & 0.019 & 0.200 & -0.030 & 0.069 \\
\hline Racial Segregation Theil Index & 0.840 & $-0.103^{*}$ & 0.058 & 0.816 & $0.139^{*}$ & 0.081 & 0.354 & -0.037 & 0.056 & 0.063 & -0.004 & 0.019 & 0.035 & 0.000 & 0.007 \\
\hline Income Segregation Theil Index & 0.233 & 0.032 & 0.067 & 0.056 & -0.004 & 0.023 & 0.052 & 0.003 & 0.023 & 0.039 & 0.001 & 0.020 & 0.037 & -0.001 & 0.010 \\
\hline Share with Commute $<15$ Mins & 0.997 & $0.327^{* * *}$ & 0.091 & 0.940 & $0.368^{* * *}$ & 0.133 & 0.840 & $0.229^{*}$ & 0.127 & 0.998 & $0.385^{* * *}$ & 0.075 & 1.000 & $0.359^{* * *}$ & 0.054 \\
\hline \multicolumn{16}{|l|}{ Income Distribution } \\
\hline Household Inc. per Capita for W.-A. A. & 0.985 & $0.446^{* * *}$ & 0.125 & 0.049 & 0.011 & 0.077 & 0.046 & 0.010 & 0.071 & 0.035 & -0.004 & 0.056 & 0.173 & -0.018 & 0.045 \\
\hline Gini Bottom $99 \%$ & 0.153 & 0.015 & 0.042 & 0.039 & -0.001 & 0.018 & 0.880 & $-0.098^{* *}$ & 0.048 & 0.069 & -0.003 & 0.015 & 0.117 & -0.008 & 0.026 \\
\hline Top 1\% Income Share for Parents & 0.418 & -0.066 & 0.088 & 0.524 & -0.133 & 0.147 & 0.040 & 0.002 & 0.017 & 0.063 & -0.006 & 0.032 & 1.000 & $-0.246^{* * *}$ & 0.048 \\
\hline \multicolumn{16}{|l|}{$\operatorname{Tax}$} \\
\hline Local Tax Rate & 0.036 & 0.000 & 0.010 & 0.038 & 0.000 & 0.012 & 0.099 & 0.009 & 0.033 & 0.226 & 0.026 & 0.056 & 0.328 & 0.028 & 0.046 \\
\hline Local Gov. Expenditures per Capita & 0.099 & -0.010 & 0.037 & 0.231 & -0.036 & 0.075 & 0.049 & 0.002 & 0.021 & 0.032 & 0.000 & 0.010 & 0.069 & -0.004 & 0.018 \\
\hline State EITC Exposure & 0.034 & 0.001 & 0.025 & 0.093 & -0.008 & 0.033 & 0.806 & 0.099 & 0.059 & 0.034 & 0.000 & 0.006 & 0.138 & 0.005 & 0.014 \\
\hline State Income Tax Progressivity & 0.051 & 0.002 & 0.013 & 0.249 & 0.023 & 0.046 & 0.912 & $0.122^{* *}$ & 0.054 & 0.783 & 0.101 & 0.066 & 0.149 & 0.006 & 0.016 \\
\hline \multicolumn{16}{|l|}{ K-12 Education } \\
\hline School Expenditure per Student & 0.040 & 0.000 & 0.011 & 0.073 & -0.004 & 0.020 & 0.093 & 0.008 & 0.032 & 0.034 & 0.000 & 0.011 & 0.045 & 0.000 & 0.008 \\
\hline Teacher-Student Ratio & 0.086 & -0.005 & 0.021 & 0.060 & 0.003 & 0.017 & 0.043 & 0.001 & 0.016 & 0.032 & 0.000 & 0.010 & 0.058 & 0.002 & 0.012 \\
\hline Test Score Percentile & 0.046 & 0.002 & 0.014 & 0.103 & 0.009 & 0.034 & 0.215 & 0.027 & 0.059 & 0.034 & 0.001 & 0.012 & 0.092 & 0.006 & 0.024 \\
\hline High School Dropout Rate & 0.039 & 0.000 & 0.008 & 0.857 & $-0.117^{*}$ & 0.062 & 0.170 & -0.019 & 0.050 & 0.032 & 0.000 & 0.010 & 0.271 & -0.025 & 0.047 \\
\hline \multicolumn{16}{|l|}{ College } \\
\hline Number of Colleges per Capita & 0.034 & 0.000 & 0.006 & 0.211 & -0.023 & 0.052 & 0.347 & -0.049 & 0.076 & 0.086 & -0.007 & 0.030 & 0.035 & 0.001 & 0.008 \\
\hline Mean College Tuition & 0.033 & 0.000 & 0.008 & 0.038 & 0.001 & 0.008 & 0.049 & 0.001 & 0.012 & 0.034 & 0.000 & 0.008 & 0.043 & 0.001 & 0.007 \\
\hline College Graduation Rate & 0.047 & 0.001 & 0.010 & 0.061 & -0.002 & 0.014 & 0.326 & 0.033 & 0.054 & 0.047 & -0.002 & 0.013 & 0.070 & 0.003 & 0.013 \\
\hline \multicolumn{16}{|l|}{ Local Labor Market } \\
\hline Labor Force Participation Rate & 0.997 & $-0.238^{* * *}$ & 0.060 & 0.046 & 0.002 & 0.020 & 0.038 & 0.000 & 0.013 & 0.197 & 0.028 & 0.064 & 0.084 & -0.006 & 0.024 \\
\hline Fraction Working in Manufacturing & 0.883 & $-0.145^{* *}$ & 0.070 & 0.989 & $-0.258^{* * *}$ & 0.072 & 1.000 & $-0.349 * * *$ & 0.062 & 1.000 & $-0.220^{* * *}$ & 0.044 & 1.000 & $-0.269^{* * *}$ & 0.038 \\
\hline Growth in Chinese Imports 1990-2000 & 0.071 & -0.002 & 0.009 & 0.107 & -0.008 & 0.028 & 0.120 & -0.019 & 0.061 & 0.038 & -0.001 & 0.019 & 0.040 & 0.001 & 0.011 \\
\hline Teenage Labor Force Participation Rate & 0.656 & -0.151 & 0.128 & 0.202 & 0.047 & 0.111 & 0.071 & 0.006 & 0.034 & 0.048 & 0.003 & 0.023 & 0.050 & 0.002 & 0.018 \\
\hline \multicolumn{16}{|l|}{ Migration } \\
\hline Migration Inflow Rate & 0.070 & 0.003 & 0.023 & 0.339 & -0.050 & 0.078 & 0.372 & -0.065 & 0.095 & 0.085 & -0.007 & 0.031 & 0.154 & -0.009 & 0.025 \\
\hline Migration Outflow Rate & 0.175 & 0.013 & 0.032 & 0.438 & -0.062 & 0.079 & 0.490 & -0.074 & 0.085 & 0.039 & 0.001 & 0.019 & 0.061 & -0.002 & 0.014 \\
\hline Fraction of Foreign Born Residents & 0.877 & $0.139 * *$ & 0.068 & 0.372 & -0.050 & 0.073 & 0.096 & -0.011 & 0.042 & 0.050 & -0.003 & 0.023 & 0.992 & $0.135^{* * *}$ & 0.035 \\
\hline \multicolumn{16}{|l|}{ Social Capital } \\
\hline Social Capital Index & 0.971 & $0.274^{* * *}$ & 0.089 & 0.569 & 0.145 & 0.146 & 0.056 & 0.003 & 0.027 & 0.034 & 0.000 & 0.014 & 0.061 & -0.004 & 0.023 \\
\hline Fraction Religious & 0.809 & 0.087 & 0.053 & 0.288 & 0.029 & 0.052 & 1.000 & $0.250 * * *$ & 0.050 & 0.999 & $0.255^{* * *}$ & 0.047 & 1.000 & $0.250^{* * *}$ & 0.052 \\
\hline Violent Crime Rate & 0.063 & 0.004 & 0.022 & 0.102 & -0.012 & 0.043 & 0.133 & -0.018 & 0.057 & 0.058 & -0.005 & 0.027 & 0.037 & 0.000 & 0.008 \\
\hline \multicolumn{16}{|l|}{ Family Structure } \\
\hline Fraction of Children with Single Mothers & 1.000 & $-0.403^{* * *}$ & 0.088 & 0.970 & $-0.445^{* * *}$ & 0.168 & 1.000 & $-0.559^{* * *}$ & 0.090 & 1.000 & $-0.719^{* * *}$ & 0.111 & 0.989 & $-0.296 * * *$ & 0.077 \\
\hline Fraction of Adults Divorced & 0.263 & -0.031 & 0.059 & 0.364 & -0.052 & 0.076 & 0.055 & -0.003 & 0.021 & 0.041 & -0.001 & 0.015 & 0.546 & -0.064 & 0.068 \\
\hline Fraction of Adults Married & 0.063 & -0.004 & 0.022 & 0.041 & 0.000 & 0.017 & 0.064 & -0.005 & 0.027 & 0.846 & $-0.239 *$ & 0.127 & 0.040 & -0.001 & 0.017 \\
\hline
\end{tabular}




\section{References}

Aaronson, D., and B. Mazumder, 2008, Intergenerational Economic Mobility in the US: 1940 to 2000, Journal of Human Resources 43, 139-172.

Autor, D. H., D. Dorn, and G. H. Hanson, 2013, The Geography of Trade and Technology Shocks in the United States, American Economic Review 103, 220-225.

Becker, G.S., and N. Tomes, 1979, An Equilibrium Theory of the Distribution of Income and Intergenerational Mobility, Journal of Political Economy 87, 1153-1189.

Becker, Gary S., 1991, A Treatise on the Family (Harvard University Press: Cambridge).

Becker, G. S., and N. Tomes, 1986, Human Capital and the Rise and Fall of Families, Journal of Labour Economics 4, 1-39.

Blanden, Jo, 2013, Cross-country Rankings in Intergenerational Mobility: A Comparison of Approaches From Economics and Sociology, Journal of Economic Surveys 27, 38-73.

Borjas, G. J., Friedman R. B., and L. F. Katz, 1997, How Much Do Immigration and Trade Affect Labor Market Outcomes?, Brookings Papers on Economic Activity 28, 1-90.

Borjas, George, 1995, Ethnicity, Neighborhoods, and Human-Capital Externalities, American Economic Review 43, 365-390.

Brock, W., and S. D. Durlauf, 2001, Growth Empirics and Reality, World Bank Economic Review 15, 229-272.

Card, David, and A. B. Krueger, 1992, Does School Quality Matter? Returns to Education and the Characteristics of Public Schools in the United States, Journal of Political Economy 100, 1-40. 
Chetty, R., N. Hendren, P. Kline, and E. Saez, 2014, Where is the Land of Opportunity? The Geography of Intergenerational Mobility in the United States, Quarterly Journal of Economics (forthcoming).

Clark, G., 2014, The Son Also Rises (Princeton University Press: USA).

Coleman, James S., 1988, Social Capital in the Creation of Human Capital, American Journal of Sociology 94, S95-S120.

Corak, M., 2013, ncome Inequality, Equality of Opportunity, and Intergenerational Mobility, Working Paper, IZA DP No. 7520.

Cutler, D., and E. Glaeser, 1997, Are Ghettos Good or Bad?, Quarterly Journal of Economics $112,827-872$.

Draper, D., 1995, Assessment and Propagation of Model Uncertainty, Journal of the Royal Statistical Society, Series B 57, 45-97.

Durlauf, S. N., A. Kourtellos, and C. M. Tan, 2008, Are Any Growth Theories Robust?, Economic Journal 118, 329-346.

Eicher, T., C. Henn, and C. Papageorgiou, 2012, Trade Creation and Diversion Revisited: Accounting for Model Uncertainty and Natural Trading Partner Effects, Journal of Applied Econometrics 27, 296-321.

Eicher, T., C. Papageorgiou, and A. E. Raftery, 2011, Default Priors And Predictive Performance In Bayesian Model Averaging, With Application To Growth Determinants, Journal of Applied Econometrics 26, 30-55.

Fernandez, C., E. Ley, and M. Steel, 2001a, Benchmark Priors for Bayesian Model Averaging, Journal of Econometrics 100, 381-427. 
— , 2001b, Model Uncertainty in Cross-Country Growth Regressions, Journal of Applied Econometrics 16, 563-576.

George, E., 1999, Discussion of Bayesian model averaging and model search strategies M. A. Clyde., in J. Bernardo, J. Berger, A. David, and A. Smith, ed.: Bayesian Statistics 6 . pp. 157-177 (Clarendon Press: Oxford).

— 2010, Dilution Priors: Compensating for Model Space Redundancy, in J. Berger, T. Cai, and I. Johnstone, ed.: Borrowing Strength: Theory Powering Applications - A Festschrift for Lawrence D. Brown . pp. 165-185 (Institute of Mathematical Statistics: Beachwood, $\mathrm{OH})$.

Hauser, R., 2010, Intergenerational Economic Mobility in the United States: Measures, Differentials, and Trends, Working Paper 9812, University of Wisconsin-Madison, Center for Demography and Ecology.

Hotz, J. V., and J. K. Scholz, 2003, The Earned Income Tax Credit, in R. A. Moffitt, ed.: Means-Tested Transfer Programs in the United States, . pp. 141-197 (University of Chicago Press: Chicago).

Ichino, A., L. Karabarbounis, and E. Moretti, 2011, The Political Economy Of Intergenerational Income Mobility, Economic Inquiry 49, 47-69.

Kass, R., and L. Wasserman, 1995, A Reference Bayesian Rest for Nested Hypotheses and its Relationship to the Schwarz Criterion, Journal of the American Statistical Association 90, 928-934.

Kass, R. E., and A. E. Raftery, 1995, Bayes Factors, Journal of the American Statistical Association 90, 773-795. 
Krueger, A., 2012, The Rise and Consequences of Inequality in the United States, Speech at the Center for American Progress, Washington D.C. on January 12, 2012.

Leamer, E. E., 1978, Specification Searches (Wiley, New York.).

Lee, C., and G. Solon, 2009, Trends in Intergenerational Income Mobility, Review of Economics Statistics 91, 776-772.

Ley, E., and M. Steel, 2012, Mixtures of g-priors for Bayesian Model Averaging with Economic Applications, Journal of Econometrics 171, 251-266.

Liang, F., R. Paulo, G. Molina, M. A. Clyde, and J. O. Berger, 2008, Mixtures of g Priors for Bayesian Variable Selection, Journal of the American Statistical Association 103, 410-423.

Magnus, J. R., and W. Wang, 2014, Concept-Based Bayesian Model Averaging and Growth Empirics, Oxford Bulletin of Economics and Statistics 76, 1468-1484.

Masanjala, W., and C. Papageorgiou, 2008, Rough and Lonely Road to Prosperity: A Reexamination of the Sources of Growth in Africa Using Bayesian Model Averaging, Journal of Applied Econometrics 23, 671-682.

Mitchell, T. J., and J. J. Beauchamp, 1988, Bayesian Variable Selection in Linear Regression, Journal of the American Statistical Association 83, 1023-1032.

Moser, M., and P. Hofmarcher, 2014, Model Priors Revisited: Interaction Terms in BMA Growth Applications, Journal of Applied Econometrics 29, 344-347.

Raftery, A., D. Madigan, and J. Hoeting, 1997, Bayesian Model Averaging for Linear Regression Models, Journal of the American Statistical Association 92, 179-191.

Raftery, A. E., 1995, Bayesian Model Selection in Social Research (with Discussion), Sociological Methodology 25, 111-196. 
Rupasingha, A., and S.J. Goetz, 2008, US County-Level Social Capital Data, 1990-2005, The Northeast Regional Center for Rural Development, Penn State University, University Park, PA.

Sala-i Martin, X., G. Doppelhofer, and R. Miller, 2004, Determinants of Long-term Growth: a Bayesian Averaging of Classical Estimates (BACE) Approach, American Economic Review 94, 813-835.

Schelling, Thomas C., 1971, Dynamic Models of Segregation, Journal of Mathematical Sociology 1, 143-186.

Wilson, William J., 1996, When Work Disappears: the World of the New Urban Poor (Knopf: Distributed by Random House, Inc.: New York). 
Appendix 
Figure A1: Model Size Distribution and Posterior Model Probabilities (g-UIP)

The red line denotes the prior model size distribution while the blue line denotes the posterior model size distribution. These results are based on the Uniform Information Priors (g-UIP).

\section{Posterior Model Size Distribution} Mean: 14.6778

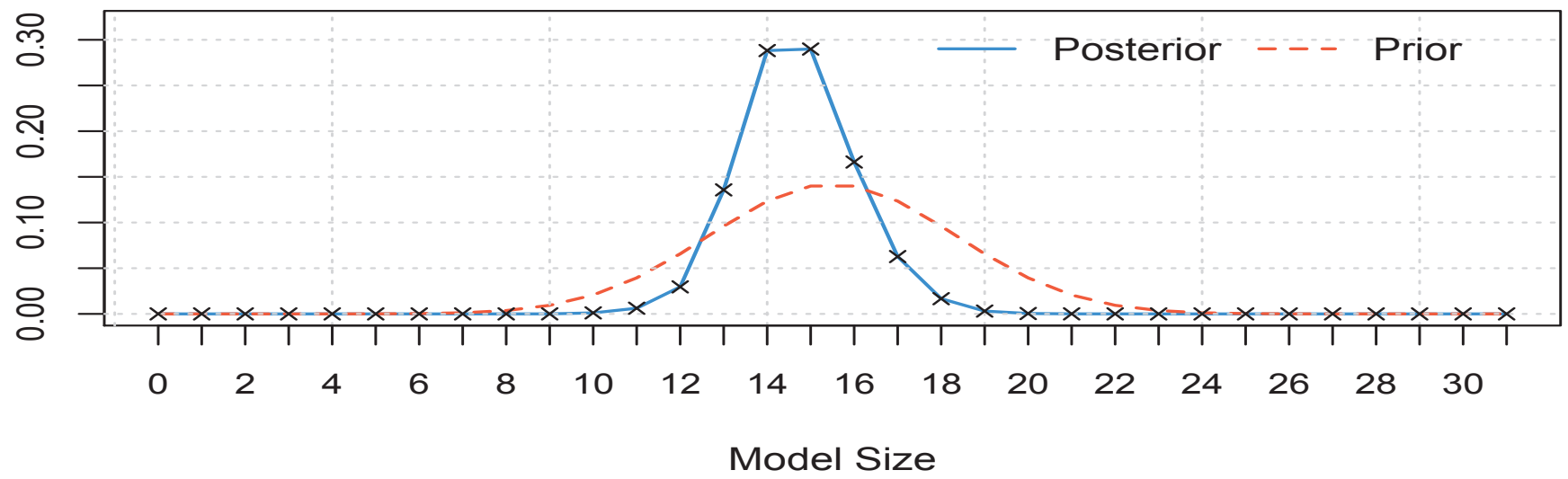

Posterior Model Probabilities (Corr: 0.9996)

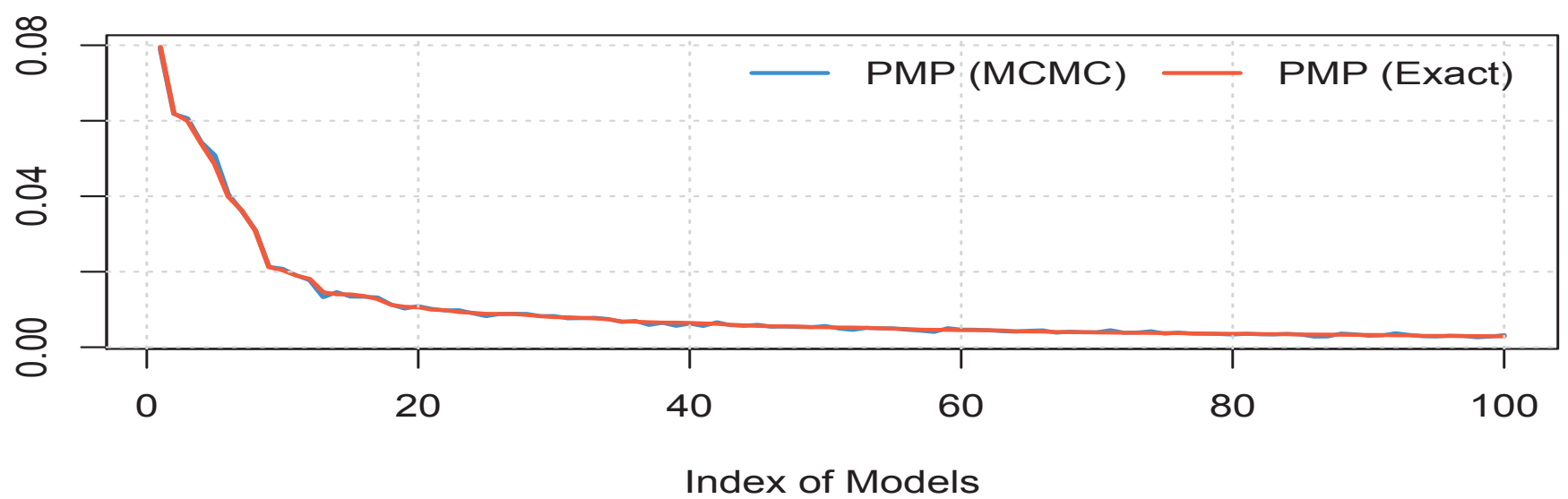


Figure A2: Regressors Included in Best Models (g-UIP)

The blue color corresponds to a positive coefficient, red to a negative coefficient, and white to non-inclusion (a zero coefficient). On the horizontal axis it shows the best 100 models, scaled by their PMPs. The intercept and the time trend are always kept in the model. These results are based on the Uniform Information Priors (g-UIP).

\section{Model Inclusion Based on Best 100 Models}

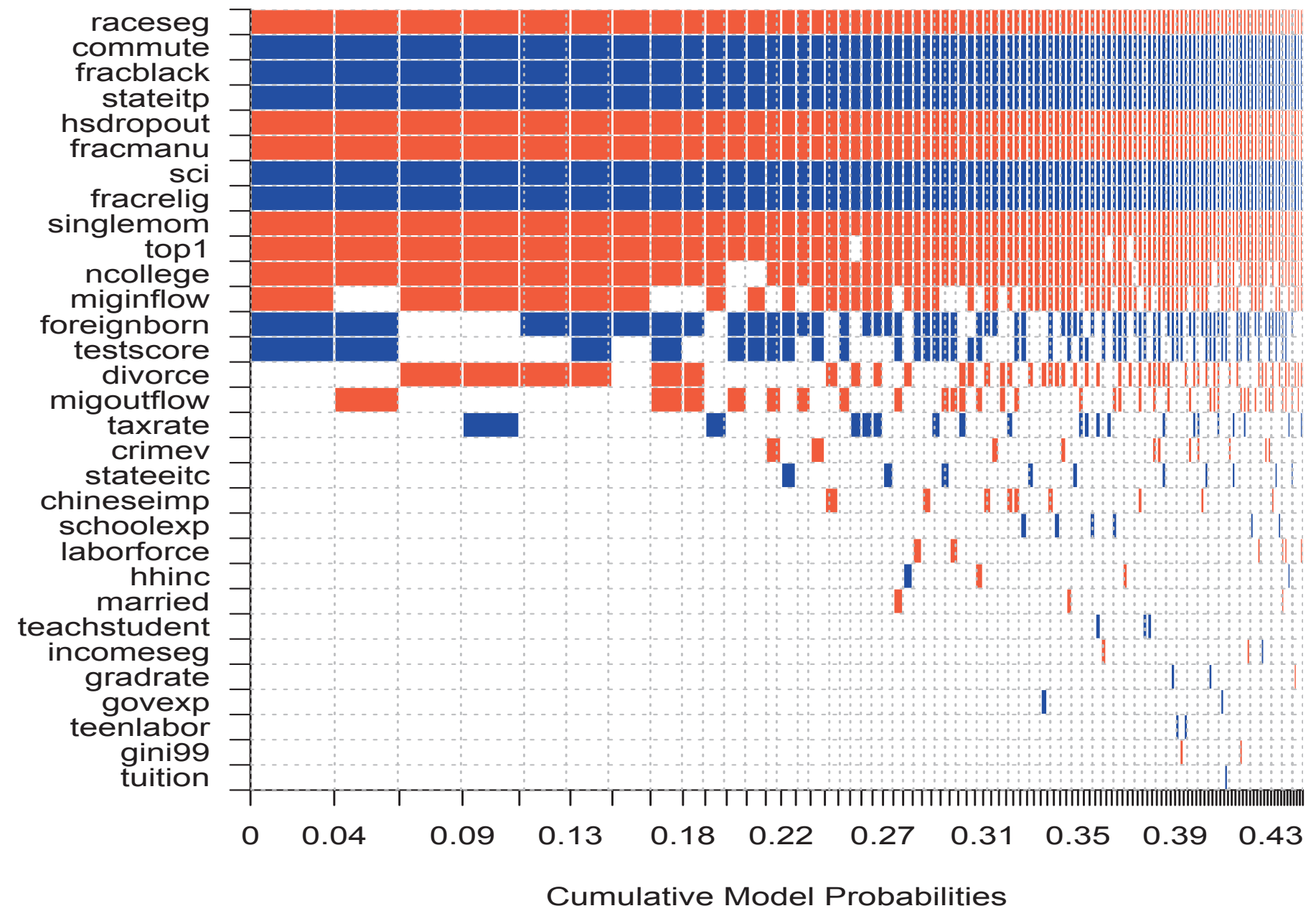




\section{Table A1: Descriptive Statistics (sample without College)}

This table reports descriptive statistics for two measures of spatial intergenerational mobility and 31 determinants across US commuting zones made available by the Equality of Opportunity Project. The statistics refer to a balanced sample of 633 commuting zones, which is a sub-sample of the one used by Chetty, Hendren, Kline, and Saez (2014). This subsample excludes the College variables to increase the sample size.

Variable

Absolute Upward Mobility

Relative Mobility

Segregation

Fraction of Black Residents

Racial Segregation Theil Index

Income Segregation Theil Index

Share with Commute $<15$ Mins

\section{Income Distribution}

Income Distribution

Household Income per Capita for Working-Age Adults

Top 1\% Income Share for Parents

Gini Bottom 99\%

Tax

Local Tax Rate

Local Government Expenditures per Capita

State EITC Exposure

State Income Tax Progressivity

K-12 Education

School Expenditure per Student

Teacher-Student Ratio

Test Score Percentile

High School Dropout Rate

Local Labor Market

Labor Force Participation Rate

Fraction Working in Manufacturing

Growth in Chinese Imports 1990-2000

Teenage Labor Force Participation Rate

Migration

Migration Inflow Rate

Migration Outflow Rate

Fraction of Foreign Born Residents

Social Capital

Social Capital Index

Fraction Religious

Violent Crime Rate

Family Structure

Fraction of Children with Single Mothers

Fraction of Adults Divorces

Fraction of Adults Married

$\begin{array}{rrrr}\text { Mean } & \text { Std. Dev. } & \text { Min } & \text { Max } \\ 44.300 & 5.733 & 26.672 & 64.019 \\ 0.324 & 0.066 & 0.068 & 0.508 \\ & & & \\ & & & \\ 0.079 & 0.126 & 0.000 & 0.658 \\ 0.134 & 0.101 & 0.000 & 0.554 \\ 0.040 & 0.031 & 0.000 & 0.138 \\ 0.452 & 0.130 & 0.156 & 0.767\end{array}$

32517.530

10.864

0.300

5419.612

5.163

0.056

17378.600

2.673

0.063

58628.390

64.788

0.447

0.020

2248.112

1.484

0.844

0.009

0.007

0.089

841.149

4.055

1.496

952.169

0.000

0.000

11529.130

21.333

6.300

6.006

16.569

0.126

$-0.001$

1.113

2.286

4.086

10.270

$-31.837$

$\begin{array}{lll}0.019 & -0.043 & 0.099\end{array}$

11.906

24.805

20.071

0.615

0.059

0.364

0.782

0.146

1.164

0.080

1.664

0.009

$-0.003$

0.437

0.005

0.001

0.002

25.405

0.016

0.017

0.040

0.010

0.000

0.003

$\begin{array}{lll}0.049 & 0.003 & 0.378\end{array}$

0.077

0.052

0.150

0.551

1.221

$-3.199$

0.171

5.266

0.002

0.001

0.000

0.203

0.096

0.574

0.053
0.017

0.082

0.040

0.434

0.045

0.373

0.156

0.695 


\section{Table A2: Short Regressions (sample without College)}

This table reports the regression coefficients and their corresponding standard errors from multivariate LS regressions of a measure of mobility on a set of determinants. These results replicate Table IX in Chetty, Hendren, Kline, and Saez (2014) using a balanced sub-sample of 633 commuting zones. Both the dependent and independent variables are standardized to have mean 0 and standard deviation 1 in the estimation so that the regression coefficient equal correlation coefficients. ${ }^{* *},{ }^{* *}$, and $*$ denote significance of the regression coefficient at $1 \%, 5 \%$, and $10 \%$, respectively.

Racial Segregation Theil Index

Gini Bottom 99\%

High School Dropout Rate

Social Capital Index

Fraction of Children with Single Mothers

Fraction Black Residents

Constant

State Fixed Effects

Population Weighted

Urban Areas Only

Adjusted R-squared

Sample Size
(1)

(2)

(3)

$-0.100 * * *$

(0.024)

$-0.006$

$(0.039)$

$-0.169 * * *$

(0.032)

$0.283^{* * *}$

(0.034)

$-0.490 * * *$

$(0.037)$

0.035

(0.022)

0.053

(0.092)

(0.022)

$\mathrm{x}$

$0.697 \quad 0.808$

633
(4)

(5)

$0.201 * * *$

$(0.033)$

$0.107^{*}$

(0.060)

0.005

(0.041)

0.072

(0.046)

$0.531^{* * *}$

(0.049)

$-0.482^{* * *}$
$(0.037)$

$-0.547^{* * *}$

(0.060)

(0.049)

0.026

$-0.010$

(0.030)

$-0.011$

(0.033)

$(0.026)$

$-0.185^{* * *}$

(0.035) (0.027)

$0.402 * * * \quad-0.279 * * *$

(0.055) (0.040)

$0.141^{* * *}-0.294^{* * *}$

(0.041) (0.033)

$0.071 \quad 0.284^{* * *}$

(0.053) (0.040)

$-0.790 * * *$

(0.044)

0.034

(0.041)

$0.045^{*}$

(0.025)

0.609

283
0.342
633

0.594

633

0.598

633 
Table A3: BMA Regressions - Posterior Model Probabilities (g-UIP)

This table reports the baseline BMA results for the regressions of a measure of mobility on the model space spanned by the various subsets of determinants. Each cell reports the posterior inclusion probability (PIP), which is the sum of posterior model probabilities over all those models that contain that variable, using the Uniform Information Priors (g-UIP).

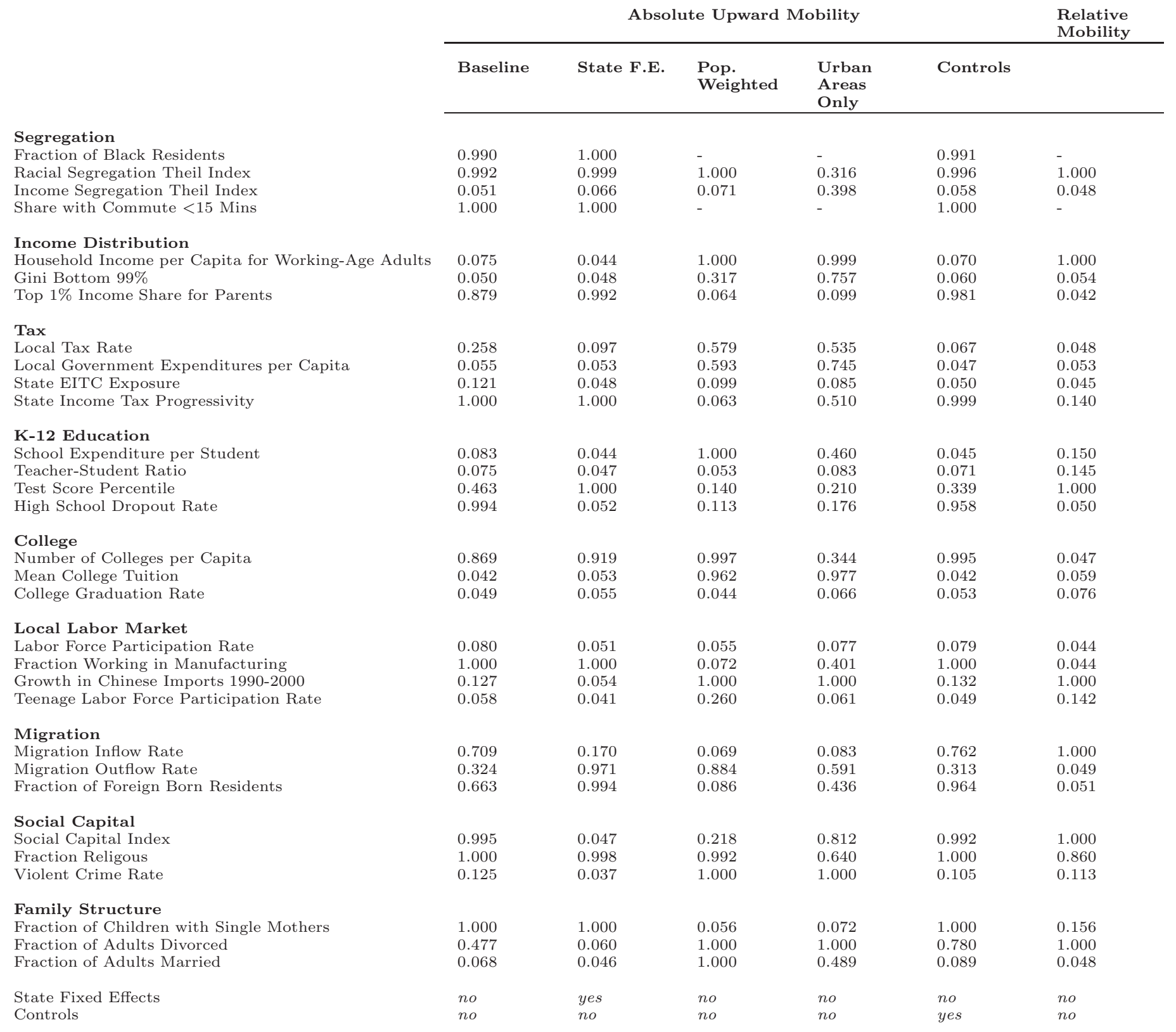


Table A4: BMA Regressions - Posterior Means and Standard Errors (g-UIP)

This table reports the posterior mean (PM) and the posterior standard error (PSE) for BMA regressions of a measure of mobility on the model space spanned by the various subsets of determinants and using the Uniform Information Priors (g-UIP). The PM is the average of the LS coefficient estimates (COEF) of individual models weighted by the posterior model probability and the PSE is the BMA estimate for the standard error (SE). ${ }^{* *}, * *$, and $*$ denote significance of the regression coefficient at $1 \%, 5 \%$, and $10 \%$,
respectively.

Absolute Upward Mobility

Relative Mobility

\begin{tabular}{|c|c|c|c|c|c|c|c|c|c|c|c|}
\hline \multicolumn{2}{|c|}{ Baseline } & \multicolumn{2}{|c|}{ State F.E. } & \multicolumn{2}{|c|}{ Pop. Weighted } & \multicolumn{2}{|c|}{ Urban Areas Only } & \multicolumn{2}{|c|}{ Controls } & \multirow[b]{2}{*}{ COEF } & \multirow[b]{2}{*}{ SE } \\
\hline COEF & $\mathrm{SE}$ & COEF & SE & COEF & SE & COEF & SE & COEF & SE & & \\
\hline $0.159^{* * *}$ & 0.045 & $0.275^{* * *}$ & 0.032 & - & & - & - & & - & $0.152^{* * *}$ & 0.042 \\
\hline$-0.078^{* * *}$ & 0.021 & $-0.082^{* * *}$ & 0.017 & $-0.097 * * *$ & 0.020 & -0.025 & 0.042 & $-0.079 * * *$ & 0.020 & $0.155^{* * *}$ & 0.017 \\
\hline 0.000 & 0.007 & -0.002 & 0.009 & 0.002 & 0.010 & -0.047 & 0.068 & 0.001 & 0.009 & -0.001 & 0.018 \\
\hline $0.270^{* * *}$ & 0.034 & $0.292^{* * *}$ & 0.029 & - & & - & - & & - & $0.260^{* * *}$ & 0.032 \\
\hline 0.001 & 0.012 & 0.000 & 0.005 & $0.223^{* * *}$ & 0.035 & $0.236^{* * *}$ & 0.057 & 0.002 & 0.014 & $-0.093^{* * *}$ & 0.019 \\
\hline-0.001 & 0.006 & -0.001 & 0.005 & -0.024 & 0.040 & -0.150 & 0.106 & -0.001 & 0.006 & 0.002 & 0.015 \\
\hline$-0.091^{* *}$ & 0.046 & $-0.127 * * *$ & 0.032 & -0.001 & 0.010 & -0.002 & 0.034 & $-0.111^{* * *}$ & 0.033 & 0.000 & 0.007 \\
\hline 0.013 & 0.026 & 0.003 & 0.013 & 0.060 & 0.059 & 0.084 & 0.093 & 0.001 & 0.008 & -0.001 & 0.010 \\
\hline 0.001 & 0.008 & 0.001 & 0.008 & 0.037 & 0.036 & 0.069 & 0.050 & 0.000 & 0.006 & -0.008 & 0.069 \\
\hline 0.003 & 0.011 & 0.001 & 0.005 & 0.004 & 0.015 & -0.002 & 0.014 & 0.000 & 0.004 & 0.000 & 0.000 \\
\hline $0.101^{* * *}$ & 0.017 & $0.168^{* * *}$ & 0.020 & 0.001 & 0.006 & 0.038 & 0.044 & $0.075^{* * *}$ & 0.017 & 0.000 & 0.000 \\
\hline 0.002 & 0.010 & 0.000 & 0.005 & $0.094^{* * *}$ & 0.017 & 0.035 & 0.044 & 0.000 & 0.005 & 0.000 & 0.001 \\
\hline 0.002 & 0.010 & 0.001 & 0.007 & 0.000 & 0.006 & 0.000 & 0.015 & 0.002 & 0.008 & 0.000 & 0.001 \\
\hline 0.032 & 0.040 & $0.193^{* * *}$ & 0.027 & 0.005 & 0.016 & 0.015 & 0.037 & 0.019 & 0.031 & $-0.005^{* * *}$ & 0.001 \\
\hline$-0.089^{* * *}$ & 0.023 & -0.001 & 0.006 & 0.005 & 0.016 & -0.012 & 0.034 & $-0.071 * * *$ & 0.025 & 0.000 & 0.000 \\
\hline$-0.061 * *$ & 0.031 & $-0.058^{* *}$ & 0.025 & $-0.094^{* * *}$ & 0.023 & -0.024 & 0.039 & $-0.087^{* * *}$ & 0.022 & 0.002 & 0.023 \\
\hline 0.000 & 0.004 & -0.001 & 0.005 & $-0.076^{* * *}$ & 0.026 & $-0.121^{* * *}$ & 0.038 & 0.000 & 0.004 & -0.004 & 0.028 \\
\hline 0.000 & 0.005 & -0.001 & 0.005 & 0.000 & 0.004 & -0.001 & 0.010 & 0.001 & 0.005 & 0.000 & 0.000 \\
\hline-0.002 & 0.011 & -0.001 & 0.006 & -0.001 & 0.005 & 0.000 & 0.011 & -0.002 & 0.011 & 0.000 & 0.002 \\
\hline$-0.236^{* * *}$ & 0.025 & $-0.182^{* * *}$ & 0.021 & 0.002 & 0.009 & -0.041 & 0.058 & $-0.166^{* * *}$ & 0.024 & 0.000 & 0.008 \\
\hline-0.003 & 0.011 & -0.001 & 0.005 & $-0.215^{* * *}$ & 0.025 & $-0.360^{* * *}$ & 0.042 & -0.004 & 0.011 & $0.227^{* *}$ & 0.023 \\
\hline 0.001 & 0.011 & 0.000 & 0.007 & -0.010 & 0.019 & 0.001 & 0.008 & -0.001 & 0.008 & 0.000 & 0.001 \\
\hline-0.056 & 0.042 & -0.010 & 0.027 & 0.002 & 0.013 & -0.001 & 0.019 & -0.069 & 0.044 & $-12.352^{* * *}$ & 2.311 \\
\hline-0.022 & 0.036 & $-0.108^{* * *}$ & 0.029 & $-0.065^{* *}$ & 0.032 & -0.081 & 0.080 & -0.023 & 0.038 & 0.004 & 0.053 \\
\hline 0.048 & 0.041 & $0.100^{* * *}$ & 0.024 & -0.001 & 0.012 & -0.055 & 0.072 & $0.082^{* * *}$ & 0.029 & -0.006 & 0.065 \\
\hline $0.139 * * *$ & 0.035 & 0.001 & 0.008 & 0.010 & 0.022 & 0.129 & 0.080 & $0.136^{* * *}$ & 0.033 & $-0.252^{* * *}$ & 0.039 \\
\hline $0.164^{* * *}$ & 0.022 & $0.097^{* * *}$ & 0.022 & $0.135^{* * *}$ & 0.035 & 0.109 & 0.100 & $0.140^{* * *}$ & 0.021 & $0.006^{* *}$ & 0.003 \\
\hline-0.006 & 0.019 & 0.000 & 0.006 & $0.160^{* * *}$ & 0.022 & $0.227^{* * *}$ & 0.033 & -0.004 & 0.015 & 0.002 & 0.007 \\
\hline$-0.462^{* * *}$ & 0.048 & $-0.462 * * *$ & 0.038 & -0.001 & 0.009 & -0.001 & 0.011 & $-0.417 * * *$ & 0.045 & 0.487 & 1.354 \\
\hline-0.032 & 0.039 & -0.002 & 0.009 & $-0.332^{* * *}$ & 0.036 & $-0.408^{* * *}$ & 0.071 & -0.058 & 0.038 & $0.447^{* * *}$ & 0.043 \\
\hline-0.002 & 0.011 & 0.000 & 0.006 & $-0.118^{* * *}$ & 0.022 & -0.039 & 0.047 & -0.003 & 0.015 & -0.002 & 0.025 \\
\hline $\begin{array}{l}\text { no } \\
\text { no }\end{array}$ & & \multicolumn{2}{|l|}{ yes } & \multicolumn{2}{|c|}{$\begin{array}{l}\text { no } \\
\text { no }\end{array}$} & \multicolumn{2}{|c|}{ no } & \multicolumn{2}{|l|}{$\begin{array}{l}\text { no } \\
\text { yes }\end{array}$} & \multicolumn{2}{|c|}{$\begin{array}{l}\text { no } \\
\text { no }\end{array}$} \\
\hline
\end{tabular}

Segregation

Fraction of Black Residents

Racial Segregation Theil Index

Income Segregation Theil Index

Share with Commute ¡15 Mins

Income Distribution

Household Income per Capita for Working-Age Ac Gini Bottom $99 \%$

Top 1\% Income Share for Parents

Tax

Local Tax Rate

Local Government Expenditures per Capita

State EITC Exposure

\section{K-12 Education}

School Expenditure per Student

Teacher-Student Ratio

High School Dropout Rate

College

Number of Colleges per Capita

College Tuition

College Graduation Rate

Local Labor Market

Labor Force Participation Rate

Fraction Working in Manufacturing

\section{Migration}

Migration Inflow Rate

Fraction of Foreign Born Residents

Social Capital

Social Capital Index

Fraction Religous

Violent Crime Rate

Fraction of Children with Single Mother

Fraction of Adults Divorced

Fraction of Adults 
Table A5: BMA Regressions - Posterior Mode Models (g-UIP)

This table reports the posterior mode models in the BMA regressions of a measure of mobility on the model space spanned by the various subsets of determinants and using the Uniform Priors (g-UIP). ${ }^{* * *},{ }^{* *}$, and ${ }^{*}$ denote significance of the regression coefficient at $1 \%, 5 \%$, and $10 \%$, respectively.

Absolute Upward Mobility

Relative Mobility

\begin{tabular}{|c|c|c|c|c|c|c|c|c|c|c|c|}
\hline \multicolumn{2}{|c|}{ Baseline } & \multicolumn{2}{|c|}{ State F.E. } & \multicolumn{2}{|c|}{ Pop. Weighted } & \multicolumn{2}{|c|}{ Urban Areas Only } & \multicolumn{2}{|c|}{ Controls } & \multirow[b]{2}{*}{ COEF } & \multirow[b]{2}{*}{ SE } \\
\hline COEF & $\mathrm{SE}$ & COEF & SE & COEF & SE & COEF & SE & COEF & SE & & \\
\hline $0.161 * * *$ & 0.034 & $0.290^{* * *}$ & 0.036 & - & - & - & - & - & - & - & - \\
\hline$-0.063^{* * *}$ & 0.026 & $-0.079^{* * *}$ & 0.024 & - & - & - & - & $-0.066^{* * *}$ & 0.026 & $0.364^{* * *}$ & 0.038 \\
\hline & & - & & - & - & - & - & - & & - & - \\
\hline $0.291 * * *$ & 0.039 & $0.321^{* * *}$ & 0.035 & - & - & - & - & $0.328^{* * *}$ & 0.035 & - & - \\
\hline - & - & - & - & $-0.164^{* * *}$ & 0.041 & $-0.360 * * *$ & 0.047 & - & - & $-0.145^{* * *}$ & 0.044 \\
\hline - & & - & - & $-0.317^{* * *}$ & 0.037 & $-0.532^{* * *}$ & 0.055 & - & - & - & - \\
\hline 0.011 & 0.036 & -0.003 & 0.027 & - & - & - & - & -0.001 & 0.032 & - & - \\
\hline - & - & - & - & - & - & - & - & - & - & - & - \\
\hline - & - & - & - & 0.029 & 0.048 & -0.031 & 0.038 & - & - & - & - \\
\hline- & - & - & - & - & - & - & - & - & - & - & - \\
\hline $0.116^{* * *}$ & 0.017 & $0.167^{* * *}$ & 0.025 & - & - & - & - & $0.058^{* * *}$ & 0.018 & - & - \\
\hline - & - & - & - & -0.048 & 0.031 & 0.030 & 0.043 & - & - & - & - \\
\hline - & - & - & - & - & - & - & - & - & - & - & - \\
\hline 0.042 & 0.028 & $0.191^{* * *}$ & 0.034 & - & - & - & - & - & - & $-0.105^{* *}$ & 0.050 \\
\hline$-0.102^{* * *}$ & 0.026 & - & - & - & - & - & - & - & - & - & - \\
\hline$-0.064 * * *$ & 0.025 & $-0.054^{* * *}$ & 0.021 & -0.017 & 0.050 & $-0.235^{* * *}$ & 0.042 & $-0.086 * * *$ & 0.027 & - & - \\
\hline & - & - & - & $-0.121 * * *$ & 0.030 & -0.038 & 0.048 & - & - & - & - \\
\hline- & - & - & - & - & - & - & - & - & - & - & - \\
\hline- & - & - & - & - & - & - & - & - & - & - & - \\
\hline$-0.230^{* * *}$ & 0.021 & $-0.157^{* * *}$ & 0.020 & - & - & $-0.380 * * *$ & 0.040 & - & - & $0.413^{* * *}$ & 0.037 \\
\hline- & - & - & - & $-0.118^{* * *}$ & 0.046 & - & - & $-0.055^{* * *}$ & 0.013 & - & - \\
\hline- & - & - & - & - & - & - & - & - & - & - & - \\
\hline$-0.067^{* * *}$ & 0.019 & - & - & - & - & - & - & - & - & - & - \\
\hline-0.001 & - & $-0.103^{* * *}$ & 0.018 & - & - & - & - & $-0.048 * * *$ & 0.018 & $-0.163^{* * *}$ & 0.037 \\
\hline - & - & $0.074^{* *}$ & 0.029 & $0.214^{* * *}$ & 0.030 & $0.316^{* * *}$ & 0.043 & $0.081^{* * *}$ & 0.028 & & \\
\hline $0.163^{* * *}$ & 0.028 & - & - & $0.445^{* * *}$ & 0.042 & $0.389^{* * *}$ & 0.056 & $0.182^{* * *}$ & 0.027 & $-0.191 * * *$ & 0.048 \\
\hline $0.165^{* * *}$ & 0.021 & $0.106^{* * *}$ & 0.025 & - & - & $0.276^{* * *}$ & 0.036 & - & - & -0.015 & 0.039 \\
\hline- & - & - & - & $-0.153^{* * *}$ & 0.040 & -0.050 & 0.037 & - & - & - & - \\
\hline$-0.523^{* * *}$ & 0.045 & -0.526 & 0.041 & - & - & - & - & $0.344^{* * *}$ & 0.030 & - & - \\
\hline & - & - & - & $-0.219 * * *$ & 0.039 & $-0.079 * *$ & 0.037 & $-0.178^{* * *}$ & 0.021 & $0.116^{* * *}$ & 0.044 \\
\hline & - & - & - & - & - & - & - & - & - & - & - \\
\hline 0.03 & & 0.32 & & 0.07 & & 0.0 & & 0.14 & & 0.15 & \\
\hline 0.03 & & 0.30 & & 0.07 & & 0.0 & & 0.14 & & 0.1 & \\
\hline no & & yes & & no & & $\mathrm{n}$ & & no & & no & \\
\hline no & & no & & no & & $\mathrm{n}$ & & yes & & no & \\
\hline
\end{tabular}


Table A6: BMA Regressions - Posterior Model Probabilities (without College, g-UIP)

This table uses a larger sample size (633 commuting zones) than our baseline results at the expense of excluding the College variables from the sample space. It reports the posterior mean (PM) and the posterior standard error (PSE) for BMA regressions of a measure of mobility on the model space spanned by the various subsets of determinants and using the Benchmark Priors (g-BRIC). Each cell reports the posterior inclusion probability (PIP), which is the sum of posterior model probabilities over all those models that contain that variable, using the Uniform Information Priors (g-UIP).

Absolute Upward Mobility

\begin{tabular}{|c|c|c|c|c|c|}
\hline \multirow[b]{2}{*}{ Baseline } & \multicolumn{3}{|c|}{ Absolute Upward Mobility } & & \multirow{2}{*}{$\begin{array}{l}\text { Relative } \\
\text { Mobility } \\
\end{array}$} \\
\hline & State F.E. & $\begin{array}{l}\text { Pop. } \\
\text { Weighted }\end{array}$ & $\begin{array}{l}\text { Urban } \\
\text { Areas } \\
\text { Only }\end{array}$ & Controls & \\
\hline 0.996 & 1.000 & - & - & 0.996 & - \\
\hline 0.988 & 0.999 & 1.000 & 0.314 & 0.990 & 1.000 \\
\hline 0.050 & 0.050 & 0.104 & 0.101 & 0.083 & 0.046 \\
\hline 1.000 & 1.000 & - & - & 1.000 & - \\
\hline 0.065 & 0.046 & 1.000 & 1.000 & 0.067 & 1.000 \\
\hline 0.055 & 0.057 & 0.181 & 0.323 & 0.062 & 0.057 \\
\hline 0.770 & 0.966 & 0.104 & 0.119 & 0.922 & 0.043 \\
\hline 0.290 & 0.124 & 0.674 & 0.533 & 0.087 & 0.047 \\
\hline 0.054 & 0.062 & 0.585 & 0.922 & 0.046 & 0.052 \\
\hline 0.140 & 0.057 & 0.064 & 0.077 & 0.061 & 0.046 \\
\hline 1.000 & 1.000 & 0.057 & 0.911 & 0.999 & 0.137 \\
\hline 0.084 & 0.048 & 1.000 & 0.297 & 0.053 & 0.148 \\
\hline 0.129 & 0.093 & 0.052 & 0.071 & 0.159 & 0.142 \\
\hline 0.609 & 1.000 & 0.200 & 0.851 & 0.610 & 1.000 \\
\hline 1.000 & 0.065 & 0.159 & 0.071 & 0.998 & 0.048 \\
\hline 0.077 & 0.048 & 0.049 & 0.064 & 0.072 & 0.045 \\
\hline 1.000 & 1.000 & 0.051 & 0.191 & 1.000 & 0.041 \\
\hline 0.121 & 0.059 & 1.000 & 1.000 & 0.121 & 1.000 \\
\hline 0.061 & 0.040 & 0.195 & 0.059 & 0.049 & 0.143 \\
\hline 0.607 & 0.157 & 0.049 & 0.078 & 0.665 & 1.000 \\
\hline 0.379 & 0.949 & 0.682 & 0.929 & 0.387 & 0.050 \\
\hline 0.759 & 0.982 & 0.087 & 0.128 & 0.974 & 0.050 \\
\hline 0.993 & 0.048 & 0.317 & 0.358 & 0.990 & 1.000 \\
\hline 1.000 & 0.998 & 0.998 & 0.267 & 1.000 & 0.858 \\
\hline 0.123 & 0.046 & 1.000 & 1.000 & 0.111 & 0.112 \\
\hline 1.000 & 1.000 & 0.052 & 0.068 & 1.000 & 0.155 \\
\hline 0.265 & 0.051 & 1.000 & 1.000 & 0.415 & 1.000 \\
\hline 0.059 & 0.061 & 1.000 & 0.202 & 0.076 & 0.047 \\
\hline no & yes & no & no & no & no \\
\hline no & no & no & no & yes & no \\
\hline
\end{tabular}

Segregation

Fraction of Black Residents

Racial Segregation Theil Index

Income Segregation Theil Index

Share with Commute $<15$ Mins

Household Income per Capita for Working-Age Adults

Gini Bottom 99\%

Top 1\% Income Share for Parents

Tax

Local Tax Rate

Local Government Expenditures per Capita

State EITC Exposure

State Income Tax Progressivity

K-12 Education

School Expenditure per Student

Teacher-Student Ratio

Test Score Percentile
High School Dropout Rate

Local Labor Market

Labor Force Participation Rate

Fraction Working in Manufacturing

Growth in Chinese Imports 1990-2000

Teenage Labor Force Participation Rate

\section{Migration}

Migration Inflow Rate

Fraction of Foreign Born Residents

\section{Social Capital}

Social Capital Index

Fraction Religious

Violent Crime Rate

Family Structure

Fraction of Children with Single Mothers

Fraction of Adults Divorced

Fraction of Adults Married

State Fixed Effects

Controls 
Table A7: BMA Regressions - Posterior Means and Standard Errors (without College, g-UIP)

This table uses a larger sample size (633 commuting zones) than our baseline results at the expense of excluding the College variables from the sample space. It reports the posterior mean (PM) and the posterior standard error (PSE) for BMA regressions of a measure of mobility on the model space spanned by the various subsets of determinants and using the Uniform Priors (g-UIP). The PM is the average of the LS coefficient estimates (COEF) of individual models weighted by the posterior model probability and the PSE is the BMA estimate for the standard error (SE). $* * *, * *$, and * denote significance of the regression coefficient at $1 \%, 5 \%$, and $10 \%$, respectively.

Absolute Upward Mobility

Relative Mobility

Segregation

Fraction of Black

Racial Segregation Theil Index

Income Segregation Theil Index

Share with Comin $<15$ Mins

Income Distribution

Household Income per Capita for Working-Age Adults

Top 1\% Income Share for Parent

Tax

Local Tax Rate

Local Government Expenditures per Capita

State Income Tax Progressivity

\section{K-12 Education}

School Expenditure per Student

Teacher-Student Ratio

Test Score Percentile

High School Dropout Rate

Local Labor Market

Labor Force Participation Rate

Fraction Working in Manufacturing

Growth in Chinese Imports 1990-2000

Teenage Labor Force Participation Rate

Migration

Migration Inflow Rate

Fraction of Foreign Born Residents

Social Capital

Social Capital Index

Fraction Religious

Violent Crime Rate

Family Structure

Fraction of Children with Single Mother

Fraction of Adults Divorced

Fraction of Adults Married

State Fixed Effects

Controls

\begin{tabular}{|c|c|c|c|c|c|c|c|c|c|c|c|}
\hline \multicolumn{2}{|c|}{ Baseline } & \multicolumn{2}{|c|}{ State F.E. } & \multicolumn{2}{|c|}{ Pop. Weighted } & \multicolumn{2}{|c|}{ Urban Areas Only } & \multicolumn{2}{|c|}{ Controls } & \multirow[b]{2}{*}{ COEF } & \multirow[b]{2}{*}{ SE } \\
\hline COEF & $\mathrm{SE}$ & COEF & $\mathrm{SE}$ & $\mathrm{COEF}$ & $\mathrm{SE}$ & COEF & SE & COEF & SE & & \\
\hline $0.176^{* * *}$ & 0.039 & $0.286^{* * *}$ & 0.032 & - & & - & & $0.181^{* * *}$ & 0.040 & - & - \\
\hline$-0.076^{* * *}$ & 0.021 & $-0.082^{* * *}$ & 0.017 & $-0.107^{* * *}$ & 0.020 & -0.024 & 0.041 & $-0.074^{* * *}$ & 0.021 & $0.155^{* * *}$ & 0.017 \\
\hline 0.000 & 0.007 & -0.001 & 0.007 & 0.004 & 0.015 & -0.005 & 0.022 & 0.003 & 0.013 & -0.001 & 0.018 \\
\hline $0.255^{* * *}$ & 0.032 & 0.270 & 0.027 & - & & - & & $0.241 * * *$ & 0.032 & - & - \\
\hline 0.001 & 0.011 & 0.000 & 0.005 & $0.193^{* * *}$ & 0.036 & $0.256^{* * *}$ & 0.047 & 0.001 & 0.014 & $-0.094 * * *$ & 0.019 \\
\hline-0.001 & 0.006 & -0.001 & 0.006 & -0.011 & 0.029 & -0.040 & 0.069 & -0.001 & 0.007 & 0.002 & 0.016 \\
\hline-0.075 & 0.050 & $-0.111^{* * *}$ & 0.036 & -0.004 & 0.017 & -0.008 & 0.033 & $-0.094^{* * *}$ & 0.040 & 0.000 & 0.007 \\
\hline 0.016 & 0.030 & 0.005 & 0.015 & 0.077 & 0.064 & 0.075 & 0.083 & 0.003 & 0.011 & -0.001 & 0.010 \\
\hline 0.001 & 0.008 & 0.001 & 0.009 & 0.038 & 0.037 & $0.099^{* *}$ & 0.043 & 0.000 & 0.006 & -0.008 & 0.068 \\
\hline 0.004 & 0.012 & 0.001 & 0.006 & 0.002 & 0.010 & -0.002 & 0.013 & 0.001 & 0.006 & 0.000 & 0.000 \\
\hline $0.103 * * *$ & 0.018 & $0.171^{* * *}$ & 0.021 & 0.001 & 0.006 & $0.095^{* *}$ & 0.042 & $0.080^{* * *}$ & 0.017 & 0.000 & 0.000 \\
\hline 0.002 & 0.011 & 0.000 & 0.006 & $0.090^{* * *}$ & 0.019 & 0.020 & 0.036 & 0.001 & 0.006 & 0.000 & 0.001 \\
\hline 0.005 & 0.015 & 0.003 & 0.014 & 0.000 & 0.006 & 0.000 & 0.013 & 0.006 & 0.017 & 0.000 & 0.001 \\
\hline 0.046 & 0.043 & $0.198^{* * *}$ & 0.028 & 0.009 & 0.021 & $0.103^{*}$ & 0.055 & 0.043 & 0.040 & $-0.005^{* * *}$ & 0.001 \\
\hline$-0.101^{* * *}$ & 0.022 & -0.001 & 0.008 & 0.008 & 0.022 & 0.001 & 0.013 & $-0.090 * * *$ & 0.021 & 0.000 & 0.000 \\
\hline-0.002 & 0.011 & -0.001 & 0.005 & -0.001 & 0.005 & 0.001 & 0.008 & -0.002 & 0.010 & 0.000 & 0.002 \\
\hline$-0.223^{* * *}$ & 0.025 & $-0.173 * * *$ & 0.021 & 0.000 & 0.006 & -0.013 & 0.033 & $-0.155^{* * *}$ & 0.025 & 0.000 & 0.008 \\
\hline-0.003 & 0.011 & -0.001 & 0.005 & $-0.205^{* * *}$ & 0.025 & $-0.338^{* * *}$ & 0.037 & -0.003 & 0.010 & $0.227^{* * *}$ & 0.023 \\
\hline 0.002 & 0.012 & 0.000 & 0.007 & -0.007 & 0.016 & 0.000 & 0.008 & 0.000 & 0.008 & 0.000 & 0.001 \\
\hline-0.044 & 0.040 & -0.010 & 0.028 & 0.000 & 0.008 & -0.002 & 0.017 & -0.054 & 0.043 & $-12.315^{* * *}$ & 2.316 \\
\hline-0.025 & 0.041 & $-0.100^{* * *}$ & 0.031 & -0.044 & 0.036 & $-0.173^{* * *}$ & 0.065 & -0.027 & 0.038 & 0.004 & 0.053 \\
\hline 0.060 & 0.036 & $0.098^{* * *}$ & 0.026 & -0.001 & 0.012 & -0.010 & 0.036 & $0.096^{* * *}$ & 0.030 & -0.006 & 0.065 \\
\hline $0.138^{* * *}$ & 0.037 & 0.001 & 0.008 & 0.018 & 0.030 & 0.042 & 0.066 & $0.130^{* * *}$ & 0.035 & $-0.252^{* * *}$ & 0.039 \\
\hline $0.162^{* * *}$ & 0.022 & $0.093^{* * *}$ & 0.022 & $0.149^{* * *}$ & 0.035 & 0.028 & 0.056 & $0.140^{* * *}$ & 0.021 & $0.006^{* *}$ & 0.003 \\
\hline-0.006 & 0.018 & 0.000 & 0.006 & $0.165^{* * *}$ & 0.023 & $0.216^{* * *}$ & 0.033 & -0.005 & 0.016 & 0.002 & 0.007 \\
\hline$-0.481^{* * *}$ & 0.047 & $-0.482 * * *$ & 0.039 & -0.001 & 0.008 & 0.001 & 0.010 & $-0.450^{* * *}$ & 0.045 & 0.481 & 1.346 \\
\hline-0.015 & 0.028 & -0.001 & 0.007 & $-0.358 * * *$ & 0.039 & $-0.546^{* * *}$ & 0.063 & -0.025 & 0.034 & $0.447^{* * *}$ & 0.043 \\
\hline-0.001 & 0.009 & 0.001 & 0.008 & $-0.133^{* * *}$ & 0.022 & -0.011 & 0.027 & -0.002 & 0.012 & -0.002 & 0.025 \\
\hline no & & yes & & no & & & & no & & no & \\
\hline no & & no & & no & & & & yes & & no & \\
\hline
\end{tabular}

